\title{
Microwave-assisted combustion synthesis of nanocrystalline ZnO
} powders using zinc nitrate and various amount of organic fuels as reactants: influence of reactant parameters- A status review

\author{
L. C. Nehru*1, a and C. Sanjeeviraja ${ }^{2, b}$ \\ ${ }^{1}$ Department of Medical Physics, Bharathidasan University, Tiruchirappalli-620 024, India \\ ${ }^{2}$ Department of Physics, Alagappa Chettiar College of Engineering \& Technology, Karaikudi-630 \\ 004, India. \\ Email: "alcnehru@yahoo.com (Corresponding Author), bsanjeeviraja2b@rediffmail.com
}

Kerwords: $\mathrm{ZnO}$, Nanomaterials, Microwave, Combustion synthesis, Reaction mechanism

\begin{abstract}
Nanocrystalline $\mathrm{ZnO}$ powders have been synthesized by a novel and simple microwaveassisted combustion synthesis method using urea, glycine, carbohydrazine and citric acid as fuels and zinc nitrate as oxidant. The starting materials were directly mixed and a slurry precursor with high homogeneity was formed due to the hygroscopicity of the reactants. The precursor could be ignited at room temperature, resulting in dry, loose and voluminous $\mathrm{ZnO}$ powders. An interpretation based on an adiabatic flame temperature, amount of gases produced during reaction for various fuel-tooxidizer molar ratios $(\psi)$, has been proposed for the nature of combustion and its correlation with the characteristics of as-synthesized product. The variation of adiabatic flame temperature $\left(\mathrm{T}_{\mathrm{ad}}\right)$ with the $\psi$ value was calculated theoretically according to the thermodynamic concept. The reaction process of the precursor was investigated by XRD techniques.
\end{abstract}




\section{Introduction}

Zinc oxide was prepared by a microwave-assisted combustion synthesis using an aqueous precursor containing zinc nitrate (oxidizer) and urea, glycine, carbohydrazide and citric acid (organic fuels) as staring materials [1]. The objective of the present study was to determine the maximum combustion temperature $\left(\mathrm{T}_{\text {measured }}\right)$ and the amount of gases produced during reaction for various fuel-to-oxidizer molar ratios $(\psi)$ and its correlation with the characteristics of as-synthesized product [2]. In this work the variation of adiabatic flame temperature $\left(\mathrm{T}_{\mathrm{ad}}\right)$ with the $\psi$ value of the discussed reactions have been calculated theoretically according to the thermodynamic concept. A possible reaction mechanism based on thermodynamic calculations and experimental results was proposed and also explained the effects of reactant composition on the combustion reaction [3]. A combustion method is a rapidly heating the aqueous solution containing stoichiometric amounts of respective metal nitrate (oxidiser) and fuels. All these fuels serve two purposes; they are source of $\mathrm{C}$ and $\mathrm{H}$, which on combustion form $\mathrm{CO}_{2}, \mathrm{H}_{2} \mathrm{O}$, liberate heat and they form complexes with the metal ions facilitating homogeneous mixing of the cations in solution. In combustion method, the exothermicity (adiabatic temperature, $\mathrm{T}_{\mathrm{ad}}$ ) of the redox reaction varies from 1000 to $1800 \mathrm{~K}$, depending upon the fuel used the nature of combustion differs from flaming to non-flaming (smouldering) [4]. In general, the typical temperature profile [5] recorded during (a) combustion synthesis and (b) synthesis process in metal oxide systems (using microwave) is shown in Fig.1. In the combustion process after reaching the ignition point, the temperature rapidly increases to a maximum and the exothermic reaction continued for less than one seconds. 



Fig.1. Typical temperature profiles (a) during combustion synthesis and (b) synthesis in metal systems. 
When a metal oxide semiconductor is to be optimized in order to carry out a certain reaction it is importnat to know (i) what type of fuels is needed (ii) how, the oxidation and valance number of the required fuel sites and (iii) what is the fuel ratio required to activate the reactant molecule. In order to answer these points, different characterization techniques have been developed to determine the surface morphology and acidity of the solid catalysts. For many years, the development and preparation of heterogeneous catalysts were considered more as alchemy than science, with the predominance of trial and error experiments. However, this approach is expensive, time-consuming and does not offer assurances on the final results. But, now-a-days the approach is scientific and involves a wide number of specific competencies of solid state chemistry, analytical chemistry, physical chemistry and spectroscopy. The calculation of stoichiometry aspects of propellant chemistry of metal oxide semiconductor are discussed elaborately in this paper.

In general, two important issues to be considered while performing any solution combustion process i.e. the nature and amount of fuel used in a combustion process. These also affects the following three competitive parameters, which subsequently affect the powder characteristics and batch size: (a) Nature of decomposition of precursor (b) Flame temperature and (c) Volume of evolved gases. For stoichiometric reaction, the amount of fuel (or fuel-to-oxidant ratio) is fixed on the basis of principle of propellant chemistry $[6,7]$. In general, a nature of combustion reaction at a variation in adiabatic flame temperature $\left(\mathrm{T}_{\mathrm{ad}}\right)$ and measured temperature $\left(\mathrm{T}_{\text {measured }}\right)$ as a function of fuel-to-oxidant ratio is shown in Fig.2. The values presented in the $\mathrm{X}$ and $\mathrm{Y}$ axes are general and highly sensitive to the system under investigation. The adiabatic flame temperatures $\left(\mathrm{T}_{\mathrm{ad}}\right)$ can be calculated (theoretical) using the thermodynamic data and combustion flame temperature can be measured by B-type thermocouple for the various reactants and products involved in the combustion reaction. It may be noted that the calculated adiabatic flame temperature $\left(\mathrm{T}_{\mathrm{ad}}\right)$ increases as a function of fuel-to-oxidant ratio and the actual measured flame temperature $\left(\mathrm{T}_{\text {measured }}\right)$ values are always lower than the calculated $\left(\mathrm{T}_{\mathrm{ad}}\right)$ values due to radiative losses, heating of air, water content in the precursor, incomplete combustion etc. (as shown in the Fig.2). The calculated situation may reach close to the 
actual situation over a wide range of fuel-to-oxidant ratio provided precursor decomposes in a single step in that range during auto-ignition phenomenon. The difference in the trend for the theoretical and actual flame temperature is due to the significant role of nature of decomposition of precursor (or kinetics of combustion reaction).

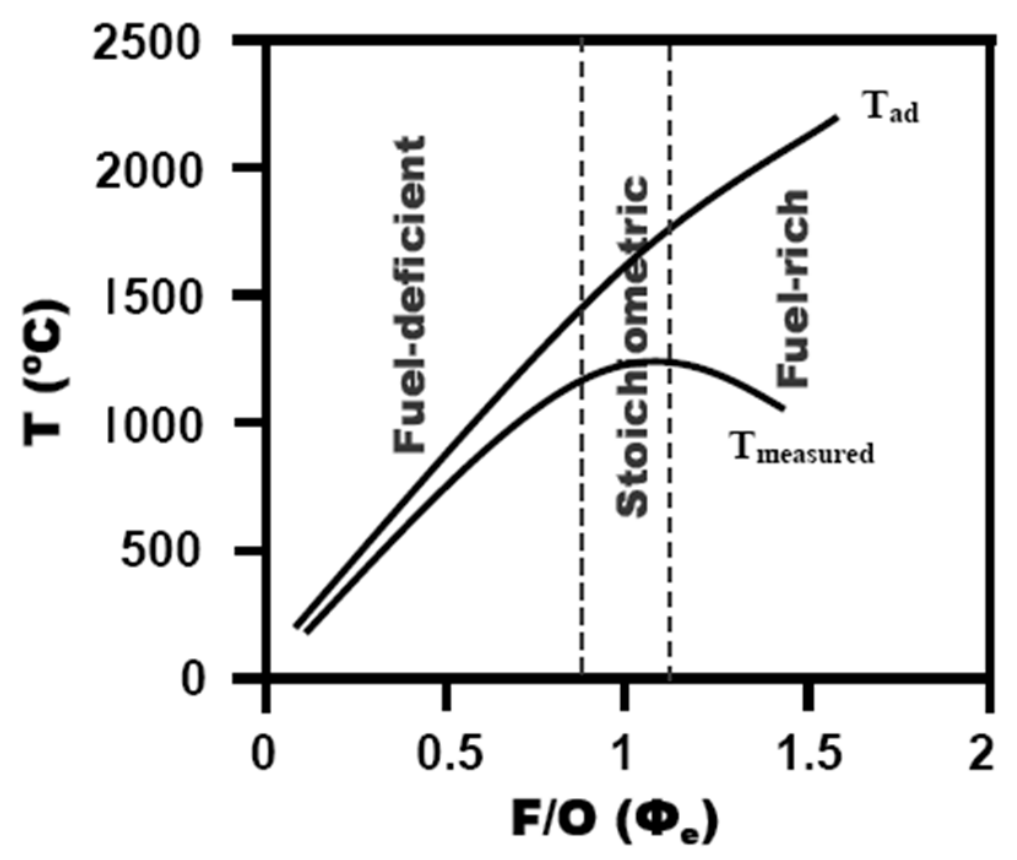

Fig. 2. A variation of adiabatic flam temperature in a function of fuel-to-oxidation ratio.

In general, for a particular fuel, the rate of decomposition of precursor decreases as fuel-tooxidant ratio increases. In spite of low flame temperature associated with the combustion of fueldeficient ratio, the overall reaction looks very violent in nature due to very fast reaction kinetics. Most of the time, it is difficult to control such kind of reactions due to very fast reaction kinetics along with sudden release of gaseous products. In addition, a considerable amount of material is lost to the surrounding and hence, it is practically impossible to scale up the batch size in this case [8]. The low flame temperature and very short residence time of flame temperature in the case of combustion reaction involving fuel-deficient precursor may result in very small primary particles in 
the form of soft agglomerates without an appreciable local partial sintering [10]. The flame temperature generated during combustion and high surface energy associated with primary nanoparticles are responsible for the formation of agglomerates among them. Strength of the agglomerates increases with flame temperature generated during combustion. Controlling the combustion reaction is an important issue for producing the powder in a significant amount. In general, it is quite difficult to scale up the fuel-deficient and stoichiometric combustion reactions due to their fast kinetics. One way of controlling the combustion reaction is to make it sluggish by using a fuel rich precursor in a range where auto-ignition phenomenon occurs [8]. This is possible due to comparatively lower flame temperature and slow reaction kinetics. It may be noted that total number of moles of evolved gases during auto-ignition and calcination steps, also increases as fuel-tooxidant ratio increases, which can results in the improved powder characteristics e.g. minimum agglomeration with high surface area.

\section{Experimental}

In this work, the $\mathrm{ZnO}$ was synthesized by microwave-assisted combustion method [9] as shown in Fig. 3. Analytic grade zinc nitrate and various organic fuels like $\mathrm{CH}_{4} \mathrm{~N}_{2} \mathrm{O}, \mathrm{C}_{2} \mathrm{H}_{5} \mathrm{NO}_{2}, \mathrm{CH}_{6} \mathrm{~N}_{4} \mathrm{O}$ and $\mathrm{C}_{6} \mathrm{H}_{8} \mathrm{O}_{7}$ were directly mixed at a desired molar ratio. From our experiment, it was found that zinc nitrate possesses hygroscopicity. The reactant mixture is easy to absorb moisture from the air to become transparent slurry. Therefore, the fuels were directly mixed at a various molar ratio with a starting solution in a beaker, stirred for 30 mins, which gives homogeneous mixtures. This clear solution was taken in a quartz container and was irradiated with microwaves in a modified domestic microwave oven (BPL India Limited, Bangalore, India, Model No. IFB, 17PG1S, microwave 700W, input range $210-230 \mathrm{~V}$-ac $50 \mathrm{~Hz}$, microwave frequency $2.45 \mathrm{GHz}$ ) to produce $\mathrm{ZnO}$ nanomaterial. A photograph of microwave-assisted combustion reaction of $\mathrm{ZnO}$ is shown in Fig.4. 




Fig. 3. Flow chart for synthesis of $\mathrm{ZnO}$ nanopowders by microwave-assisted combustion method.

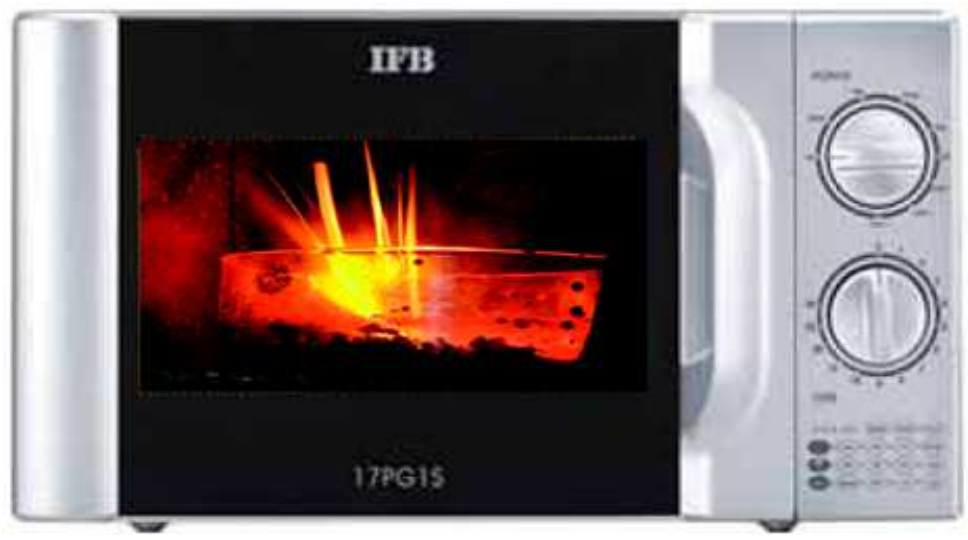

Fig. 4. Microwave oven for the powder synthesis. 
The dried mixture (here after termed as precursor) possesses the characteristic of combustion, and can be ignited to start combustion reaction by using a mini gas burner at room temperature. On doing so, combustion of the precursor with the evolution of a large volume of gases occurs, producing a loose product. It was found that, the combustion reaction is depending on the molar ratio of fuel-tooxidation. The variation in adiabatic flame temperature $\left(\mathrm{T}_{\mathrm{ad}}\right)$ with the molar ratio of fuel-to-zinc nitrate $(\psi)$, and amount of gases produced can be calculated theoretically for various molar ratios using thermodynamics data which are available from the literature are listed in Table 1. The combustion characteristics of different reactions modes are presented and discussed below.

Table 1. Relevant thermodynamic data [11].

\begin{tabular}{|c|c|c|c|c|}
\hline Compound $^{\mathrm{a}}$ & $\begin{array}{c}\Delta{H^{\circ}}_{\mathrm{f}}\left(25^{\circ} \mathrm{C}\right) \\
(\mathrm{kcal} / \mathrm{mol})\end{array}$ & $\begin{array}{c}\Delta \mathrm{G}^{\circ}\left(25^{\circ} \mathrm{C}\right) \\
(\mathrm{kcal} / \mathrm{mol})\end{array}$ & $\begin{array}{c}\mathbf{S}^{\circ} \\
\mathrm{J} / \mathrm{mol} \mathrm{K}\end{array}$ & $\begin{array}{c}\mathrm{Cp} \\
(\mathrm{kcal} / \mathrm{mol} \mathrm{K})\end{array}$ \\
\hline $\mathrm{Zn}\left(\mathrm{NO}_{3}\right)_{2} \cdot 6 \mathrm{H}_{2} \mathrm{O}_{(\mathrm{c})}$ & -550.92 & -369.6 & 180.7 & 0.0722 \\
\hline Urea $_{(\mathrm{c})}$ & -79.55 & -47.0 & 104.6 & 0.02223 \\
\hline Glycine (c) & -79.71 & -88.038 & 103.5 & $0.019+0.00131 \mathrm{~T}^{\mathrm{b}}$ \\
\hline Carbohydrazide $_{(\mathrm{c})}$ & - & - & - & - \\
\hline${\text { Citric } \text { acid }_{(\mathrm{c})}}$ & -368.75 & -298.3 & 166.2 & \\
\hline $\mathrm{ZnO}_{(\mathrm{c})}$ & -83.24 & -76.55 & 43.7 & 0.009625 \\
\hline $\mathrm{O}_{2(\mathrm{~g})}$ & 0 & $\mathbf{0}$ & 205.2 & $5.92+0.00367 \mathrm{~T}^{\mathrm{b}, \mathrm{c}}$ \\
\hline $\mathrm{N}_{2(\mathrm{~g})}$ & $\mathbf{0}$ & $\mathbf{0}$ & 191.6 & $6.50+0.0010 \mathrm{~T}^{\mathrm{b}}$ \\
\hline $\mathrm{CO}_{2(\mathrm{~g})}$ & -93.986 & -94.2 & 213.8 & $10.34+0.00274 \mathrm{~T}^{\mathrm{b}}$ \\
\hline $\mathrm{H}_{2} \mathrm{O}_{(\mathrm{g})}$ & -57.752 & -54.6 & 70.0 & $7.20+0.0036 \mathrm{~T}^{\mathrm{b}}$ \\
\hline $\mathrm{NO}_{(\mathrm{g})}$ & 21.80 & 20.922 & 210.8 & $6.46+0.00179 \mathrm{~T}^{\mathrm{b}, \mathrm{c}}$ \\
\hline $\mathrm{N}_{2} \mathrm{O}_{5(\mathrm{~g})}$ & 3.17 & 27.968 & 355.7 & $5.13+0.0817 \mathrm{~T}^{\mathrm{b}, \mathrm{c}}$ \\
\hline
\end{tabular}

${ }^{\mathrm{a}}(\mathrm{c})=$ Crystalline,$(\mathrm{g})=$ gas $;{ }^{\mathrm{b}} \mathrm{T}=$ Absolute temperature and ${ }^{\mathrm{c}}$ Calculated from discrete values. 


\section{Results and Discussion}

Reaction mechanism in thermodynamic analysis and phenomena of combustion synthesis. Use of suitable raw material in combustion synthesis ensures stability of the chemical composition and high quality of products. More importantly, it must be readily available and convenient to use. In addition, the reactants proportions can be tuned in order to have a non-violent reaction and should only produce non-toxic gases $\left(\mathrm{CO}_{2}, \mathrm{H}_{2} \mathrm{O}\right.$ and $\left.\mathrm{N}_{2}\right)$. In the present work, different organic fuels are selected typically urea $\left(\mathrm{CH}_{4} \mathrm{~N}_{2} \mathrm{O}\right.$; denoted $\left.\mathrm{U}\right)$, glycine $\left(\mathrm{C}_{2} \mathrm{H}_{5} \mathrm{NO}_{2}\right.$; denoted $\left.\mathrm{G}\right)$, carbohydrazide $\left(\mathrm{CH}_{6} \mathrm{~N}_{4} \mathrm{O}\right.$; denoted $\left.\mathrm{CH}\right)$ and citric acid $\left(\mathrm{C}_{6} \mathrm{H}_{8} \mathrm{O}_{7}\right.$; denoted $\left.\mathrm{CA}\right)$. It is also worthwhile to mention that this process uses an exothermic and rapid chemical reaction to form the final products. Again, these materials are inexpensive and generate good heat of combustion (urea is $-2.98 \mathrm{kcal} / \mathrm{g}$, glycine is $-3.24 \mathrm{kcal} / \mathrm{g}$, carbohydrazide is $-3.07 \mathrm{kcal} / \mathrm{g}$ and citric acid is $-2.76 \mathrm{kcal} / \mathrm{g}$ ). Carbohydrazide have been described as useful materials and intermediate in many areas such as boiler water treatment, metallic materials antiseptic, passivating agent, oxygen scavenger, curative intermediates and so on. Carbohydrazide is also widely used in coordination compounds. It may coordinate with many metal cations as monodentate of multidentate. Because of the ramification of hydrazine possesses strong reduction ability, it has been used to design a variety of compounds with explosive properties. On the other hand, zinc nitrate $\left[\mathrm{Zn}\left(\mathrm{NO}_{3}\right)_{2} \cdot 6 \mathrm{H}_{2} \mathrm{O}\right]$ is utilized in the present study because of its dual role as zinc source and oxidant. This research work is focused on the observation the effect of the fuel-tooxidant molar ratio (i.e., the molar ratio of fuel-to-zinc nitrite, which is hereafter referred to as $\psi$ ) on the nature of combustion reaction and the characteristics of as-synthesized powders by XRD. In order to understand the nature of combustion, variation in adiabatic flame temperatures $\left(\mathrm{T}_{\mathrm{ad}}\right)$ with the molar ratio of fuel-to-zinc nitrate $(\psi)$ and amount of gases produced can be calculated using thermodynamics data. First we consider the decomposition reaction of one mole of zinc nitrate to produce one mole of zinc oxide can be one among various alternatives, leading to the evolution of different gases, as follows:

$\mathrm{Zn}\left(\mathrm{NO}_{3}\right)_{2} \cdot 6 \mathrm{H}_{2} \mathrm{O} \rightarrow \mathrm{ZnO}_{(\mathrm{c})}+6 \mathrm{H}_{2} \mathrm{O}_{(\mathrm{g})}+\mathrm{N}_{2(\mathrm{~g})}+2.5 \mathrm{O}_{2(\mathrm{~g})}$ 
$\mathrm{Zn}\left(\mathrm{NO}_{3}\right)_{2} \cdot 6 \mathrm{H}_{2} \mathrm{O} \rightarrow \mathrm{ZnO}_{(\mathrm{c})}+6 \mathrm{H}_{2} \mathrm{O}_{(\mathrm{g})}+2 \mathrm{NO}_{(\mathrm{g})}+1.5 \mathrm{O}_{2(\mathrm{~g})}$

$\mathrm{Zn}\left(\mathrm{NO}_{3}\right)_{2} \cdot 6 \mathrm{H}_{2} \mathrm{O} \rightarrow \mathrm{ZnO}_{(\mathrm{c})}+6 \mathrm{H}_{2} \mathrm{O}_{(\mathrm{g})}+\mathrm{N}_{2} \mathrm{O}_{5}(\mathrm{~g})$

Using the thermodynamic data (Table 1$)$, the Gibbs free energy changes $\left(\Delta \mathrm{G}^{\mathrm{o}}\right)$ was calculated. The change in free energy $\left(\Delta \mathrm{G}^{\circ}\right)$ associated with a chemical reaction is a useful indicator to identify the spontaneous reaction. If a reaction is favorable for both enthalpy $\left(\Delta \mathrm{H}^{\circ}<0\right)$ and entropy $(\Delta \mathrm{S}>0)$, then the reaction will be SPONTANEOUS $\left(\Delta \mathrm{G}^{\circ}<0\right)$ at any temperature or a reaction is unfavorable for both enthalpy $(\Delta \mathrm{H}>0)$ and entropy $(\Delta \mathrm{S}<0)$, then the reaction will be NONSPONTANEOUS $(\Delta \mathrm{G}>0$ ) at any temperature and the reaction is favorable for only one of either entropy or enthalpy, the standard-state free energy equation must be used to determine whether the reaction is spontaneous or not.

Since the change in free energy is equal to the maximum useful work which can be accomplished by the reaction of zinc nitrate. The four quantities called "thermodynamic potentials" are useful in the chemical thermodynamics of reactions and non-cyclic processes. They are internal energy, the enthalpy, the Helmholtz free energy and the Gibbs free energy. The Gibbs free energy $\left(\Delta \mathrm{G}^{\circ}\right)$ is defined by:

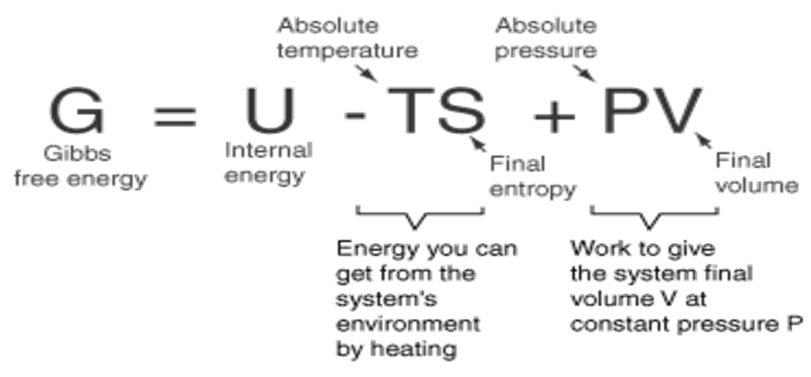

The internal energy $U$ might be thought of as the energy required creating a system in the absence of changes in temperature or volume. But as discussed in defining enthalpy, an additional amount of work PV must be done if the system is created from a very small volume in order to "create room" for the system. As discussed in defining the Helmholtz free energy, an environment at constant 
temperature T will contribute an amount TS to the system, reducing the overall investment necessary for creating the system. This net energy contribution for a system created in environment temperature $\mathrm{T}$ from a negligible initial volume is the Gibbs free energy. The change in Gibbs free energy, $\Delta \mathrm{G}$, in a reaction is a very useful parameter. It can be thought of as the maximum amount of work obtainable from a reaction. To calculate the Gibbs free energy value is changes due to the oxidation of different organic fuels [12]. The reactions involved in the combustion synthesis and the corresponding enthalpy change, starting with reaction equation (4 to 7) which describes the combustion reaction of urea (total valencies +6 ), glycine (total valencies +9 ) and citric acid (total valencies +18 ) . This reaction, being exothermic, should supply the heat needed for the synthesis reaction.

$$
\begin{aligned}
& \mathrm{CO}\left(\mathrm{NH}_{2}\right)_{2(\mathrm{c})}+1.5 \mathrm{O}_{2(\mathrm{~g})} \rightarrow \mathrm{CO}_{2(\mathrm{~g})}+2 \mathrm{H}_{2} \mathrm{O}_{(\mathrm{g})}+\mathrm{N}_{2(\mathrm{~g})} \\
& \mathrm{C}_{2} \mathrm{H}_{5} \mathrm{NO}_{2(\mathrm{c})}+2.75 \mathrm{O}_{2(\mathrm{~g})} \rightarrow 2 \mathrm{CO}_{2(\mathrm{~g})}+2.5 \mathrm{H}_{2} \mathrm{O}_{(\mathrm{g})}+\mathrm{NO}_{(\mathrm{g})} \\
& \mathrm{CH}_{6} \mathrm{~N}_{4} \mathrm{O}_{(\mathrm{c})}+2 \mathrm{O}_{2(\mathrm{~g})} \rightarrow \mathrm{CO}_{2(\mathrm{~g})}+3 \mathrm{H}_{2} \mathrm{O}_{(\mathrm{g})}+2 \mathrm{~N}_{2(\mathrm{~g})} \\
& \mathrm{C}_{6} \mathrm{H}_{8} \mathrm{O}_{7(\mathrm{c})}+4.5 \mathrm{O}_{2(\mathrm{~g})} \rightarrow 6 \mathrm{CO}_{2(\mathrm{~g})}+4 \mathrm{H}_{2} \mathrm{O}_{(\mathrm{g})}
\end{aligned}
$$

The energy associated with a chemical reaction that can be used to do this work. The free energy of a system is the sum of its enthalpy $(\Delta \mathrm{H})$ plus the product of the temperature (Kelvin) and the entropy $(\Delta S)$ of the system. The Gibbs free energy of reaction at standard state conditions is $\Delta \mathrm{G}^{\mathrm{o}}=\Delta \mathrm{H}^{\mathrm{o}}$ $\mathrm{T} \Delta \mathrm{S}^{\mathrm{o}}$. First to calculate the enthalpy $\left(\Delta \mathrm{H}^{\mathrm{o}}\right)$, entropy $\left(\Delta \mathrm{S}^{\mathrm{o}}\right)$ and Gibbs free energy $\left(\Delta \mathrm{G}^{\mathrm{o}}\right)$ for the above reaction to determine whether the reaction is spontaneous or not, chemical reaction enthalpy (heat of reaction) is defined according to the following equation [13]:

$$
\begin{aligned}
& \Delta \mathrm{S}^{\circ}=\Sigma \mathrm{nS}_{\text {Products }}^{\circ}-\Sigma \mathrm{nS}^{\circ}{ }_{\text {Reactants }} \\
& \Delta \mathrm{H}^{\circ}=\left(\Sigma \mathrm{n} \Delta \mathrm{H}_{\mathrm{f}}^{\circ}\right)_{\text {Products }}-\left(\Sigma \mathrm{n} \Delta \mathrm{H}_{\mathrm{f}}^{\circ}\right)_{\text {Reactants }}
\end{aligned}
$$


where $\mathrm{n}$ is the number of the mole, $\Delta \mathrm{H}_{\mathrm{f}}^{\mathrm{o}}$ is a standard molar enthalpy (heat) of formation at $298.15 \mathrm{~K}$ in $\mathrm{KJ} / \mathrm{mol}, \mathrm{S}^{\mathrm{o}}$ is the standard molar entropy at $298.15 \mathrm{~K}$ in $\mathrm{KJ} / \mathrm{mol}$ using the thermodynamic data listed in Table 1.

The free energy $\left(\Delta G^{\circ}\right)$ involved in each reaction using equation (4 to 7) can be calculated as a function of temperature for the combustion reaction of urea, glycine and citric acid are plotted in Fig.5 and Fig.6.

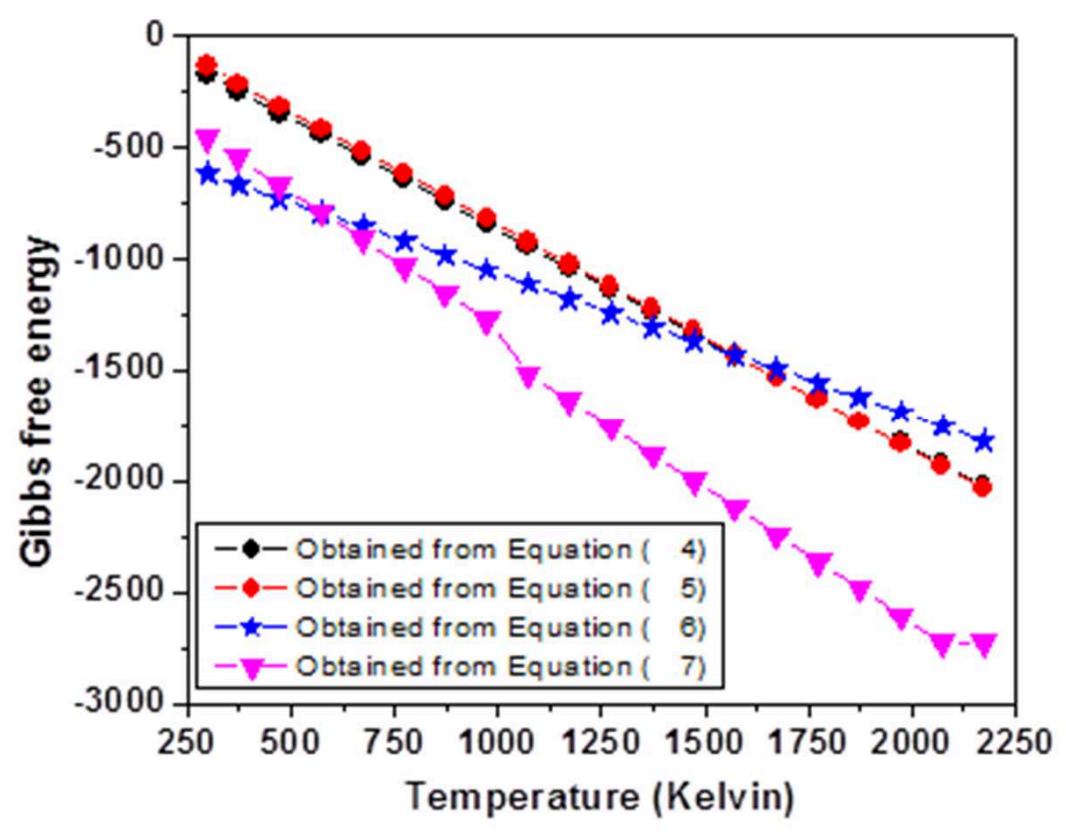

Fig.5. Effect of temperature on the Gibbs free energy change of the various $\mathrm{ZnO}$ synthesis reaction using zinc nitrate, depending on the reaction products. 


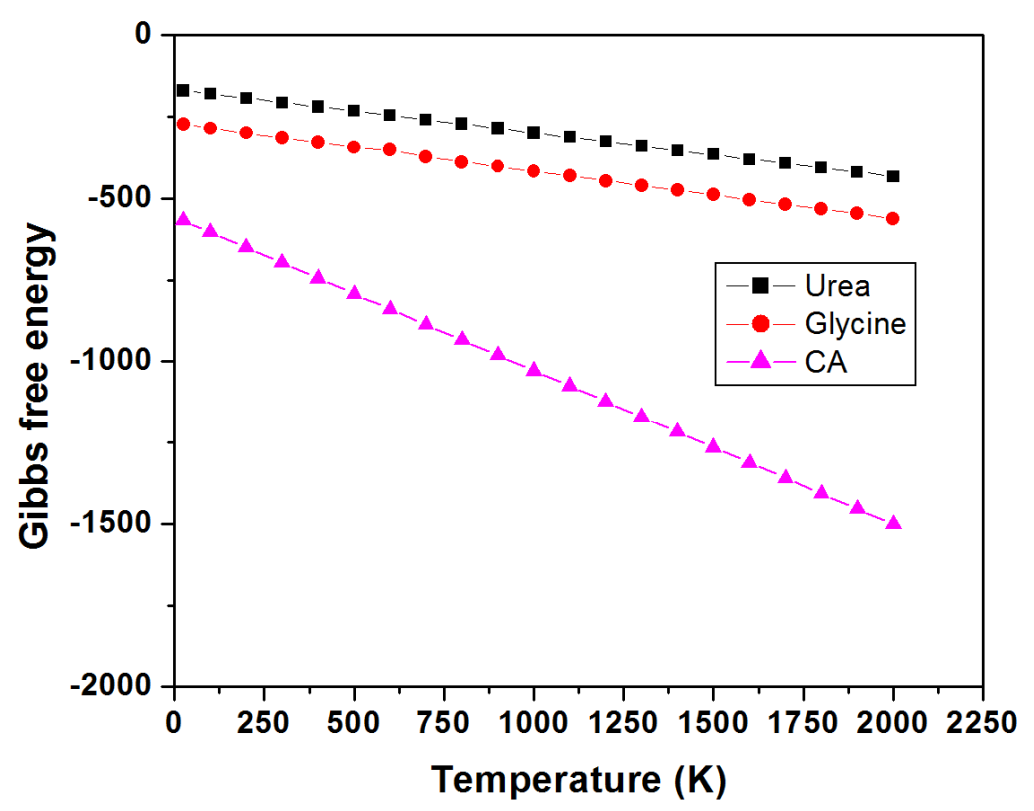

Fig.6. Effect of temperature on the Gibbs free energy change of the various fuels depending on the reaction products.

Note that the negative values of $\Delta \mathrm{G}^{\mathrm{o}}$ show the formation of products from the reactants. The curves in Fig.5 show that, while the combustion of urea is always exothermic (spontaneous), the three alternative reactions that produce $\mathrm{ZnO}$ are endothermic at low temperature and the reaction described by equation (1) becomes spontaneous above $400^{\circ} \mathrm{C}$, remaining the most favoured reaction up to $1500^{\circ} \mathrm{C}$ for all the fuels. The Gibbs free energy of carbohydrazide fuel was not calculated because there is no entropy $\left(\mathrm{S}^{\mathrm{o}}\right)$ value is reported in the thermodynamic standard data. By simple calcination, the zinc nitrates can, of course, be decomposed into zinc oxide upon heating to or above the phase transformation temperature. A constant external heat supply is necessary in this case, to maintain the system at the high temperature required accomplishing the synthesis of the appropriate phase. In combustion synthesis, the energy released from the exothermic reaction between the nitrates and the fuel, which is usually ignited at a temperature much lower than the actual phase formation temperature, can rapidly heat the system to a high temperature and sustain it long enough, even in the absence of an external heat source, for the synthesis to occur. 
The basis of the combustion synthesis technique comes from the thermochemical concepts used in the field of propellants and explosives. The need for a clear indication of the effective constitution of a fuel-oxidizer mixture as described by Jain et al. [6] to devise a simple method of calculating the oxidizing to reducing character of the mixture. The method consists on establishing a simple valency balance, frequently, of whether the elements are present in the oxidizer or in the fuel components of the mixture, to calculate the stoichiometric composition of the redox mixture which corresponds to the release of the maximum energy for the reaction. The assumed valencies are presented by the elements in the usual products of the combustion reaction, which are $\mathrm{CO}_{2}, \mathrm{H}_{2} \mathrm{O}$ and $\mathrm{N}_{2}$. Therefore, the elements carbon and hydrogen are considered as reducing elements with the corresponding valencies +4 and +1 , oxygen is considered an oxidizing element with the valency -2 and nitrogen is considered as having a valency of zero. The extrapolation of this concept to the combustion synthesis of zinc oxide at various reactions (zinc nitrate with fuels) involved in the combustion synthesis can be expressed (but over-simplified) as follows:

$\mathrm{Zn}\left(\mathrm{NO}_{3}\right)_{2} \cdot 6 \mathrm{H}_{2} \mathrm{O}_{(\mathrm{c})}+\psi \mathrm{CO}\left(\mathrm{NH}_{2}\right)_{2}(\mathrm{c})+(1.5 \psi-2.5) \mathrm{O}_{2}(\mathrm{~g}) \rightarrow \mathrm{ZnO}_{(\mathrm{c})}+(1+\psi) \mathrm{N}_{2(\mathrm{~g})}+\psi \mathrm{CO}_{2}(\mathrm{~g})+(2 \psi$ $+6) \mathrm{H}_{2} \mathrm{O}_{(\mathrm{g})}$

$$
\begin{aligned}
& \mathrm{Zn}\left(\mathrm{NO}_{3}\right)_{2} \cdot 6 \mathrm{H}_{2} \mathrm{O}_{(\mathrm{c})}+\psi \mathrm{NH}_{2} \mathrm{CH}_{2} \mathrm{COOH}_{(\mathrm{c})}+(2.25 \psi-2.5) \mathrm{O}_{2(\mathrm{~g})} \rightarrow \mathrm{ZnO}_{(\mathrm{c})}+(1+0.5 \psi) \mathrm{N}_{2(\mathrm{~g})}+2 \psi \mathrm{CO}_{2(\mathrm{~g})} \\
& +(2.5 \psi+6) \mathrm{H}_{2} \mathrm{O}_{(\mathrm{g})}
\end{aligned}
$$

$\mathrm{Zn}\left(\mathrm{NO}_{3}\right)_{2} \cdot 6 \mathrm{H}_{2} \mathrm{O}_{(\mathrm{c})}+\psi \mathrm{CH}_{6} \mathrm{~N}_{4} \mathrm{O}_{(\mathrm{c})}+(2 \psi-2.5) \mathrm{O}_{2(\mathrm{~g})} \rightarrow \mathrm{ZnO}_{(\mathrm{c})}+(1+2 \psi) \mathrm{N}_{2(\mathrm{~g})}+\psi \mathrm{CO}_{2(\mathrm{~g})}+(3 \psi+$ 6) $\mathrm{H}_{2} \mathrm{O}_{(\mathrm{g})}$

$$
\mathrm{Zn}\left(\mathrm{NO}_{3}\right)_{2} \cdot 6 \mathrm{H}_{2} \mathrm{O}_{(\mathrm{c})}+\psi \mathrm{CH}_{6} \mathrm{H}_{8} \mathrm{O}_{7(\mathrm{c})}+(4.5 \psi-2.5) \mathrm{O}_{2(\mathrm{~g})} \rightarrow \mathrm{ZnO}_{(\mathrm{c})}+\mathrm{N}_{2(\mathrm{~g})}+6 \psi \mathrm{CO}_{2(\mathrm{~g})}+(4 \psi+6) \mathrm{H}_{2} \mathrm{O}_{(\mathrm{g})}
$$


Table 2. Summary of data for the combustion technique.

\begin{tabular}{|c|c|c|c|c|c|c|}
\hline Fuel & $\Psi$ (mole) & $\begin{array}{c}\text { Fuel-to- } \\
\text { nitrate } \\
\text { molar } \\
\text { ratio } \\
\end{array}$ & $\begin{array}{c}\text { Amount of } \\
\text { gases } \\
\text { produced } \\
(\text { mole })^{\mathrm{a}}\end{array}$ & $\begin{array}{c}\text { enthalpy } \\
\left(\Delta \mathbf{H}^{\circ}\right)^{b}\end{array}$ & $\begin{array}{c}\text { Adiabatic } \\
\text { temperatures } \\
\left(\mathbf{T}_{\mathrm{ad}}{ }^{\circ} \mathbf{C}\right)^{\mathrm{c}}\end{array}$ & $\begin{array}{c}\text { Measured flame } \\
\text { temperatures } \\
\left({ }^{\circ} \mathbf{C}\right)^{\mathrm{d}}\end{array}$ \\
\hline \multirow[t]{6}{*}{ Urea } & 1.4 & 0.7 & 12.6 & -60.75 & 335 & 178 \\
\hline & 1.6 & 0.8 & 13.4 & -86.74 & 566 & 484 \\
\hline & 1.667 & 0.8335 & 13.668 & -95.44 & 639 & 569 \\
\hline & 1.8 & 0.9 & 14.2 & -112.72 & 765 & 511 \\
\hline & 2 & 1 & 15 & -138.71 & 937 & 476 \\
\hline & 2.2 & 1.1 & 15.8 & -164.70 & 1092 & 398 \\
\hline \multirow[t]{9}{*}{ Glycine } & 0.7 & 0.35 & 105 & -55.68 & 360 & 206 \\
\hline & 0.9 & 0.45 & 11.5 & -106.21 & 878 & 532 \\
\hline & 1 & 0.5 & 12 & -131.47 & 1113 & 968 \\
\hline & 1.11 & 0.555 & 12.55 & -159.25 & 1355 & 1276 \\
\hline & 1.3 & 0.65 & 13.5 & -207.26 & 1689 & 1183 \\
\hline & 1.5 & 0.75 & 14.5 & -257.79 & 2026 & 1146 \\
\hline & 1.7 & 0.85 & 15.5 & -308.32 & 2249 & 1104 \\
\hline & 1.9 & 0.85 & 16.5 & -358.85 & 2474 & 1042 \\
\hline & 2 & 1 & 17 & -384.11 & 2576 & 987 \\
\hline \multirow[t]{10}{*}{ Carbohydrazide } & 0.6 & 0.3 & 10.6 & -43.74 & 231 & 137 \\
\hline & 0.8 & 0.4 & 11.8 & -98.70 & 786 & 518 \\
\hline & 1 & 0.5 & 13 & -153.67 & 1275 & 872 \\
\hline & 1.2 & 0.6 & 14.2 & -208.64 & 1702 & 1192 \\
\hline & 1.25 & 0.625 & 14.5 & -222.38 & 1801 & 1228 \\
\hline & 1.3 & 0.65 & 14.8 & -236.12 & 1884 & 1167 \\
\hline & 1.5 & 0.75 & 16 & -291.09 & 2112 & 1088 \\
\hline & 1.7 & 0.85 & 17.2 & -346.05 & 2445 & 1024 \\
\hline & 1.9 & 0.95 & 18.4 & -401.01 & 1669 & 967 \\
\hline & 2 & 1 & 19 & -428.50 & 2770 & 927 \\
\hline \multirow[t]{9}{*}{ Citric acid } & 0.3 & 0.15 & 10 & -6.68 & 218 & 169 \\
\hline & 0.4 & 0.2 & 11 & -49.31 & 248 & 209 \\
\hline & 0.5 & 0.25 & 12 & -91.92 & 537 & 507 \\
\hline & 0.55 & 0.275 & 12.5 & -113.23 & 837 & 679 \\
\hline & 0.6 & 0.3 & 13 & -134.54 & 992 & 624 \\
\hline & 0.7 & 0.35 & 14 & -177.16 & 1265 & 563 \\
\hline & 0.8 & 0.4 & 15 & -219.78 & 1497 & 505 \\
\hline & 0.9 & 0.45 & 16 & -262.39 & 1698 & 483 \\
\hline & 1 & 0.5 & 17 & -305.01 & 1871 & 447 \\
\hline
\end{tabular}

Using the thermodynamic data for various reactants and products listed in Table 2, the enthalpy of reaction for the above equations can be calculated as follows [11]: The corresponding enthalpy change of reaction as a function of the $\psi$, 
$\Delta \mathrm{H}^{\mathrm{o}}=121.168-\psi 129.94$ for urea

$\Delta \mathrm{H}^{\mathrm{o}}=121.168-\psi 252.642$ for glycine

$\Delta \mathrm{H}^{\mathrm{o}}=121.168-\psi 274.834$ for carbohydrazide and

$\Delta \mathrm{H}^{\mathrm{o}}=121.168-\psi 426.174$ for citric acid

This reaction, being exothermic, should supply the heat needed for the synthesis reaction. The calculated enthalpies for combustion reactions of various stoichiometries ratios of urea and glycine as a fuel of zinc nitrate are summarized in Table 2 and as shown in the Fig.7. It has been observed that the enthalpy of combustion reaction $\left(\Delta \mathrm{H}^{\circ}\right)$ varies linearly with respect to fuel ratios as shown in Fig.7.

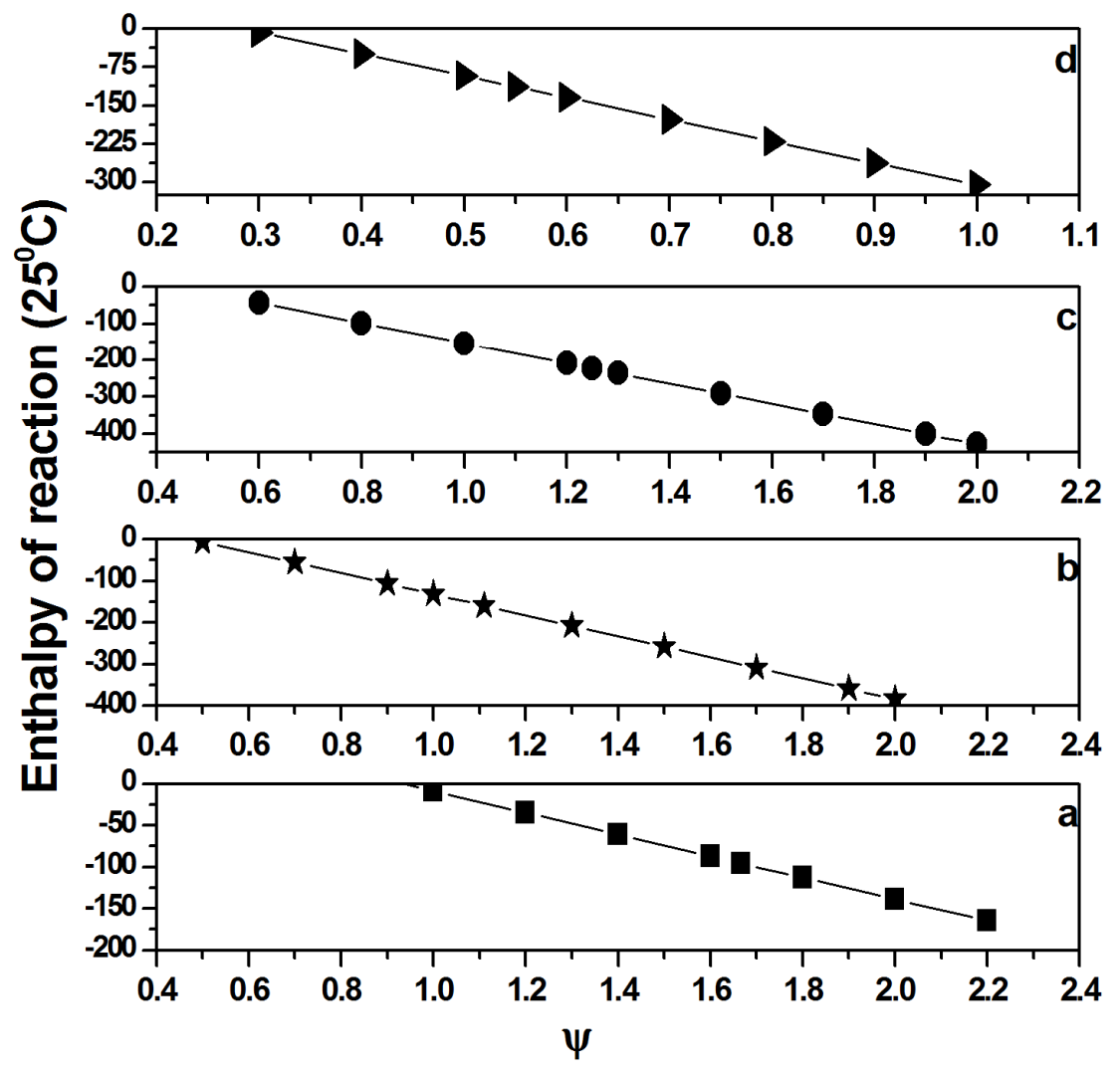

Fig.7. Entalphy reaction of (a) urea, (b) glycine, (c) carbohydrazide and (d) citric acid molar ratio for $\mathrm{ZnO}$ powders. 
The enthalpies of each reactant and the function of the $\psi$ value were consolidated in the Table 2 . When complete combustion occurs using equation (9 and 10), the only gaseous products obtained are $\mathrm{N}_{2}, \mathrm{CO}_{2}$ and $\mathrm{H}_{2} \mathrm{O}$, making this an environmentally clean processing technique. The large amount of gases formed can result in the appearance of a flame. Where $\psi$ is the molar ratio of fuel-to-zinc nitrate. Note that $\psi$ is the corresponding to the situation of "equivalent stoichiometric ratio", which implies that the oxygen content of zinc nitrate can be completely reacted to oxidize/consume equivalently. As a result, $\mathrm{ZnO}$ product and $7+4 \psi$ (for urea), $7+5 \psi$ (for glycine), $7+6 \psi$ (for carbohydrazide) and $7+10 \psi$ (for citric acid) mole gases of $\mathrm{CO}_{2}, \mathrm{H}_{2} \mathrm{O}$ and $\mathrm{N}_{2}$ can be formed directly from the reaction between fuel and oxidizer without the necessity of getting oxygen from outside. If complete combustion is assumed, the gaseous product amounts liberated in combustion reactions with urea, glycine, carbohydrazide and citric acid are shown in Table 2. It can be observed that a greater number of moles of gas are produced in combustion reactions with carbohydrazide as shown in the Fig. 8.

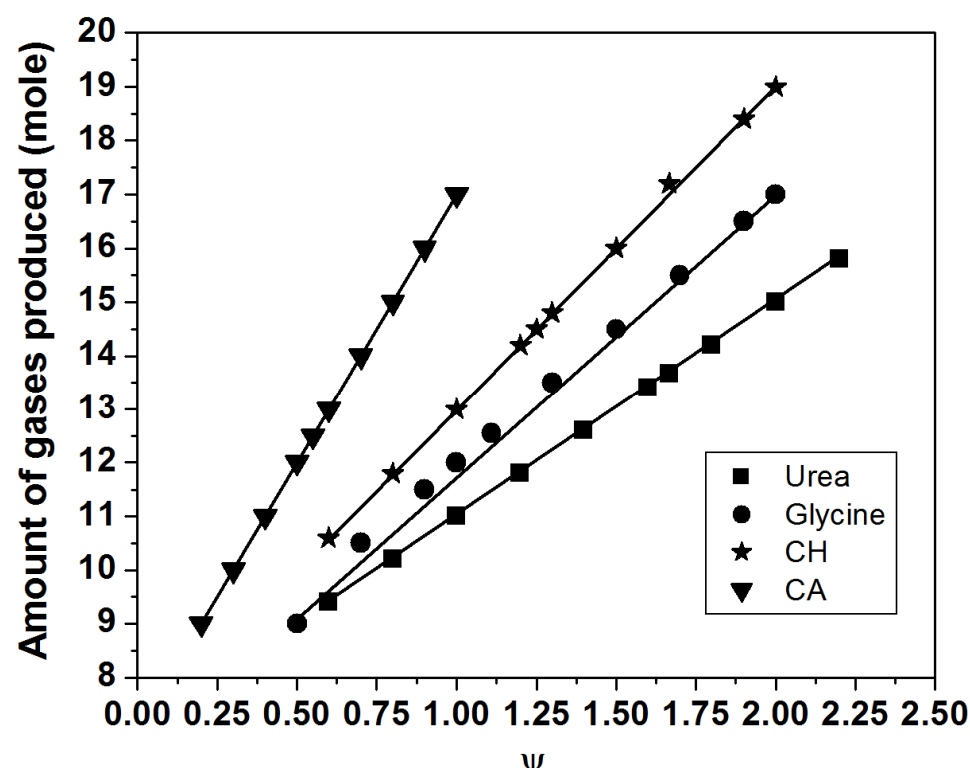

Fig.8. Amount of gaseous products. 
Reaction Phenomena. During the characteristic temperatures of combustion synthesis reaction, the four important temperature factors may affect the process of reaction and the properties of final product. They are (i) Initial temperature $\left(\mathrm{T}_{\mathrm{o}}\right)$ which is the average temperature of the reactant sample before the reaction is ignited in the propagating mode, (ii) Ignition temperature $\left(\mathrm{T}_{\mathrm{ig}}\right)$ which represents the point at which the combustion reaction is dynamically activated without further external heat supply, (iii) Adiabatic combustion temperature $\left(\mathrm{T}_{\mathrm{ad}}\right)$, which is the maximum combustion temperature achieved under adiabatic conditions and (iv) The actual combustion measured temperature $\left(\mathrm{T}_{\text {measured }}\right)$, which is the maximum temperature achieved under normal configuration and non-adiabatic conditions. Heat transfer, incomplete combustion and dissociation all result in lower temperature. One of the most important calculations chemical thermodynamics allows us to make the adiabatic flame temperature $\left(\mathrm{T}_{\mathrm{ad}}\right)$. The maximum adiabatic flame temperature for a given fuel and oxidizer combination occurs with a stoichiometric mixture (correct proportions such that all fuel and all oxidizer are consumed where fuel are burned completely). Stoichiometric mixtures have very nearly the highest adiabatic flame temperatures possible for the chemical systems under consideration. An initial view of the concept of adiabatic flame temperature $\left(\mathrm{T}_{\mathrm{ad}}\right)$ is provided by examining $\mathrm{N}_{2}$ and $\mathrm{CO}_{2}$ reacting gases, at a given pressure and at the end of temperature. The process is shown schematically in Fig.2 $\left(\mathrm{T}_{\mathrm{ad}}\right)$, where temperature is plotted versus the function of fuel-to-oxidation ratio of the completion reaction. The solid line in the figure shows a representation of the "actual" process at end of the process the maximum temperature occurs near the stoichiometric mixture ratio. This maximum temperature occurs at a completion reaction changes into two parts. First process of the reaction is at a constant temperature (T) and constant pressure (P). For this process, we would need to extract heat. For the overall process there is no work done and no heat exchanged so that the difference in enthalpy between initial and final states is zero. The temperature change during this second process, the tendency for the adiabatic flame temperature $\left(\mathrm{T}_{\mathrm{ad}}\right)$ means $100 \%$ completion of the reaction. We find the adiabatic flame temperature $\left(\mathrm{T}_{\mathrm{ad}}\right)$ in three ways: (a) an approximate solution using an average value of specific heat $\left(\mathrm{C}_{\mathrm{p}}\right)$, (b) a more accurate 
one using the tabulated evolution of $\mathrm{C}_{\mathrm{p}}$ with temperature or (c) a more accurate solution using the tabulated values for gas enthalpy in Table 1 . The variation in adiabatic flame temperature $\left(\mathrm{T}_{\mathrm{ad}}\right)$ is influenced by the type of fuel, molar ratio of fuel-to-zinc nitrate $(\psi)$ and the amount of water remaining in the precursor solution at the ignition temperature. The flame temperature can be increased with the addition of excess oxidizer such as zinc nitrate, or by increasing the fuel/oxidizer molar ratio. The $\mathrm{T}_{\mathrm{ad}}$ is the maximum temperature to which the product can be raised if the exothermic reaction is performed in adiabatic conditions. The equations ( 8 and 13) can be used for the theoretical calculation of adiabatic flame temperature $\left(\mathrm{T}_{\mathrm{ad}}\right)$ using a combustion reaction value, which can be calculated on the basis of the following general equations [14]:

$$
Q=-\Delta H^{\circ}=\int_{298}^{T_{a d}}\left(\sum n . C_{p}\right)_{\text {Products }} d T
$$

where $\mathrm{Q}$ is the heat absorbed by products under adiabatic condition, $\Delta \mathrm{H}^{\circ}{ }_{298}$ is the enthalpy of reaction at $298 \mathrm{~K}, \mathrm{n}$ is the number of the mole, $\mathrm{C}_{\mathrm{p}}$ (product) is the heat capacity of the products at constant pressure and $\mathrm{T}_{\mathrm{ad}}$ the adiabatic temperature at which the reaction is raised. The adiabatic temperatures $\left(\mathrm{T}_{\mathrm{ad}}\right)$ are calculated by substituting the thermodynamic data from Table 1 and the appropriate enthalpies of reactions equation (13) into equations (14). The adiabatic flame temperature for the combustion reaction between fuels and zinc nitrate with various molar ratios $(\psi)$ can be calculated. The plot of the maximum measured combustion temperature $\left(\mathrm{T}_{\text {measured }}\right)$ as a function of the $\psi$ value, as well as the characteristic combustion regimes are shown in Fig.9.

It is clear from the data in Table 2 and from the Fig.9, which the reaction enthalpies increase rapidly with fuel content in the mixture and the excess heat generated raises the adiabatic temperatures during combustion. The measured values of temperature ( $\left.\mathrm{T}_{\text {measured }}\right)$ increases by increasing the $\psi$ value to a maximum of stoichiometric balance (at $\Phi_{\mathrm{e}}=1$ ) conditions and then decreases with further increase in the molar ratio. It has been observed that the adiabatic flame temperatures resulting from 
the presence of excess of fuel in the reaction mixture. High temperatures are usually generated during the decomposition of fuels called an exothermic process. This formula shows that the adiabatic flame temperatures not only depend on the nature of the fuel but also on the fuel to nitrate ratio (depending on the value of $\Psi$ ). Nevertheless, when the reaction occurs, it is well known that the measured values of the combustion measured temperatures $\left(\mathrm{T}_{\text {measured }}\right)$ are typically much lower than calculated values of adiabatic flame temperature $\left(\mathrm{T}_{\mathrm{ad}}\right)$ as a result of heat dissipation, incomplete combustion and heating of air (ambient). The former may be the major factor, since a considerable amount of gas generated during the combustion reaction could cause a violent gas evolution and thus a certain amount of reaction heat is carried away through convective heat loss, resulting in a lower $\mathrm{T}_{\text {measured }}$ value when compared with the corresponding theoretical $\mathrm{T}_{\mathrm{ad}}$. Also, $\mathrm{T}_{\text {measured }}$ values tend to increase with decreasing fuels $(\Psi)$ ratio upto a point after which they tend to decrease. Combustion reactions involving fuel-deficient mixtures $\left(\Phi_{\mathrm{e}}>1\right)$ are generally slow, essentially flameless and result in powders with poor crystallinity. Reactions involving stoichiometric mixtures $\left(\Phi_{\mathrm{e}}=1\right.$ i.e., the oxygen content of zinc nitrate is exactly sufficient to consume/oxidize the fuel completely) are relatively fast reactions that yield crystalline zinc oxide powders. 

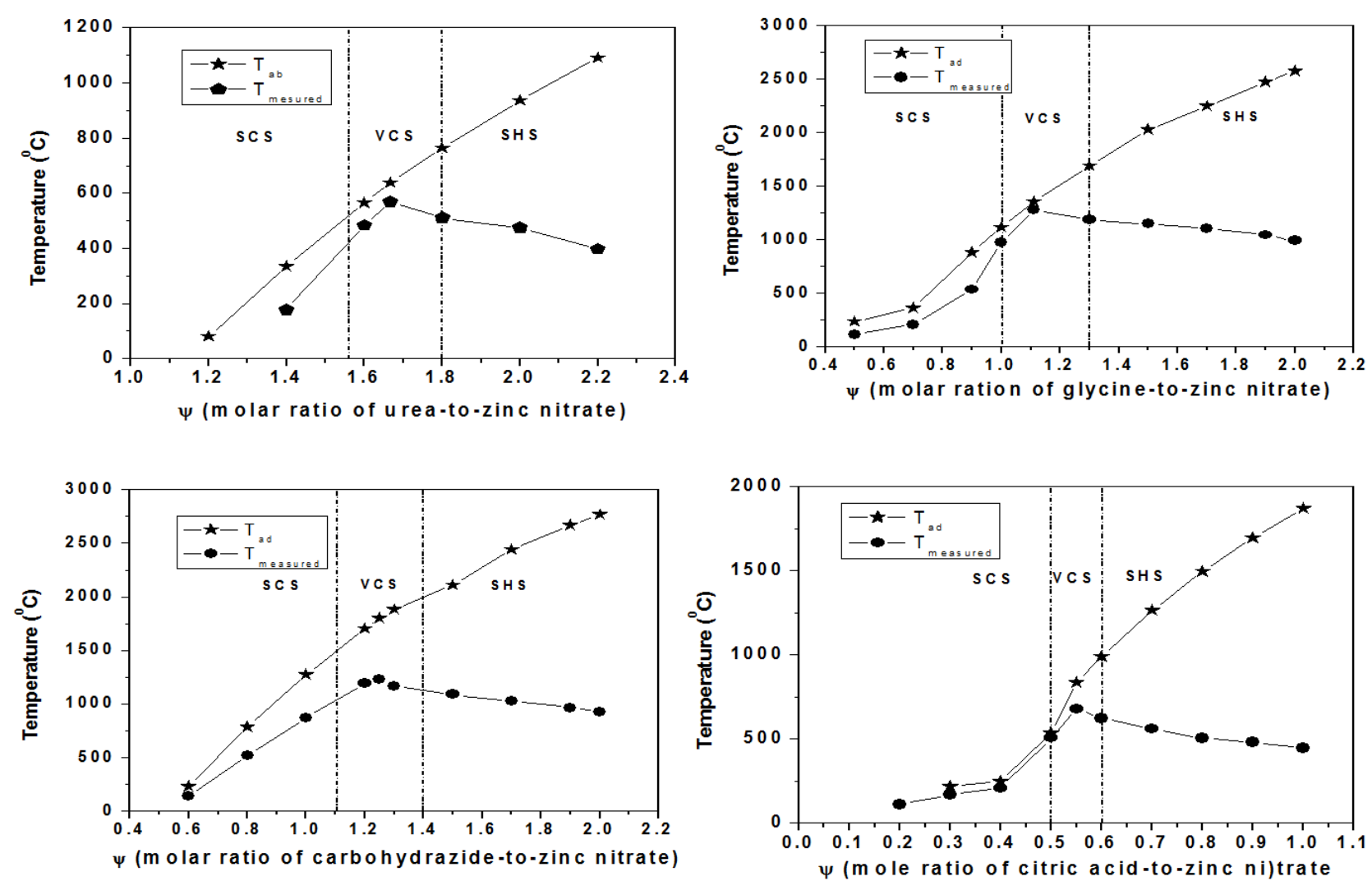

Fig.9. Adiabatic flame temperature $\left(\mathrm{T}_{\mathrm{ad}}\right)$ and measured maximum combustion temperature $\left(\mathrm{T}_{\text {measured }}\right)$ achieved for different combustion mode as a function of the molar ratio of fuels $(\Psi)$.

When the precursor mixtures contain excess fuel, the combustion reactions need oxygen to be supplied externally. Since this process is limited by the diffusion rate, the combustion process tends to be relatively slower. However, the obtained products are found to crystalline and having a relatively small grain size. As noted above, depending on $\Phi_{\mathrm{e}}$, the reaction can proceed in three different modes of combustion:

1. Smoldering combustion synthesis (SCS), when $\Phi_{\mathrm{e}}>1.11$ (fuel-deficient condition); an excess amount of oxygen in the reactant mixture is present and stifled the reaction. That's why this mode is characterized by a slow and flameless reaction with minimum combustion temperature $\left({ }^{\circ} \mathrm{C}\right)$. 
2. Volume combustion synthesis (VCS), when $\Phi_{\mathrm{e}}=1.11$, (stoichiometric condition); a thermal explosion takes place and the reaction occurred in the solution volume, resulting in the formation of a homogenous solid. The whole oxygen content of the zinc nitrates can react completely in oxidizing the fuel, so the maximum temperature $\left({ }^{\circ} \mathrm{C}\right)$ is obtained for this stoichiometric condition.

3. Self-propagating high-temperature synthesis (SHS), when $\Phi_{\mathrm{e}}<1.11$ (fuel-rich condition); the reaction is locally ignited and propagates as a combustion wave in a self-sustained manner through the reaction volume. In this condition, atmosphere oxygen is required for a complete combustion between fuel and zinc nitrates. So the temperature $\left({ }^{\circ} \mathrm{C}\right)$ is decreasing from maximum to minimum.

SCS mode is characterized by a relatively slow, essentially flameless reaction. Since the fuel content is small, the heat evolved is not enough and thus the temperature is lower. This leads to slower reaction rates as manifested in the smoldering combustion behavior. Moreover, it was experimentally observed that below the $\Phi_{\mathrm{e}}$ value of below 1.11, combustion reaction ceases to occur. In this regime, the $\Phi_{\mathrm{e}}$ value of below 1.11 was taken as a representative fuel-deficient ratio. Extremely fast reaction characterizes the VCS mode. In this case, it is important that the reaction occurs essentially simultaneously in the reaction volume. Since the fuel-to-oxidant ratio is within a proper range $\left(1.05<\Phi_{\mathrm{e}}<1.90\right)$, while the oxygen content contained in the precursor is the main source of oxygen required for combustion reaction. Once the oxygen, which comes from $\mathrm{NO}_{3}^{-}$, is generated, it immediately reacts with fuels and oxidizes/consumes and thus results in the phenomenon of VCS reaction. Finally, the characteristic feature of the SHS mode is that reaction initiates locally and propagates as a combustion wave in a self-sustained manner through the reaction volume. When there is excess fuel, the combustion reaction needs oxygen supplied externally. Oxygen enters through diffusion into the reaction zone by kinetic factors that limit the reaction rate and, eventually, the SHS reaction mode. 
Since these combustion reactions occur in shorter duration at higher temperatures, the dissipation of heat produced during combustion process would be negligible. Contrary, the amount of produced gas, $\mathrm{n}_{\text {gas }}$, increases with the increase of fuel content. The theoretical values of $\Delta \mathrm{H}^{0}, \mathrm{n}_{\text {gas }}$ and $\mathrm{T}_{\mathrm{ad}}$ are presented in the Table 2. The thermochemical concepts from propellant chemistry [6, 8], to determine the urea needed to balance the total oxidizing and reducing valencies in the mixture of oxidizer and fuel should be zero. In this case, to calculate the total valencies of the $\mathrm{Zn}\left(\mathrm{NO}_{3}\right)_{2} \cdot 6 \mathrm{H}_{2} \mathrm{O}$ is -10 . These valences should be balanced by the total "reducing valencies" of the urea (fuel) is +6 . The water molecules do not affect the total valencies of the nitrate and therefore it is irrelevant for the chemistry of the combustion. Thus, the stoichiometric composition of the redox mixture to release the maximum energy for the reaction, leads to: $(-10)+(+6) \psi=0$ and the stoichiometric composition of the redox mixture, to release the maximum energy for the reaction, would demand that $\psi=1.667$ mole of urea were used [16]. The overall synthesis reaction, which is endothermic and, therefore, requires the use of urea, would be reaction equations $(9=1+\Psi 4)$. From the thermodynamic point of view and based on the equations $(9,1$ and 4), for the $\mathrm{ZnO}$ synthesis reaction equation (9) to occur at $25^{\circ} \mathrm{C}$, on the basis of enthalpy reactions solely, $\left(\Delta \mathrm{H}^{\circ}=121.168-\psi 129.94=\right.$ 0 ), only $\psi=0.93$ mole of urea would be needed.

These 0.93 mole of urea provide the enthalpy requirement for complete decomposition at $25{ }^{\circ} \mathrm{C}$ and release of all the corresponding gases, as predicted by reaction of the equation (9) (i.e. $1.105 \mathrm{O}_{2(\mathrm{~g})}$ $\left.+1.93 \mathrm{~N}_{2(\mathrm{~g})}+0.93 \mathrm{CO}_{2(\mathrm{~g})}+7.86 \mathrm{H}_{2} \mathrm{O}_{(\mathrm{g})}\right)$. How with the stoichiometric urea content specified by the ever, this temperature is not enough to promote the propellant chemistry calculations, or lower, were found to crystallization of the oxide. Even to raise the temperature for the spontaneous decomposition of the nitrate (the heat generated will be absorbed by the evolved gases and the oxide), the combustion of extra moles of urea is necessary. The required total urea content was calculated from the thermodynamic data (Table 1 and equation (9)) to be 1.35 mole. This value is still lower than the specified propellant chemistry calculations. The combustion of the extra 0.737 mole of urea specified by the propellant chemistry calculations (i.e. $1.67-0.93=0.737$ mole), will 
raise the temperature of all the final products. This temperature is high enough to decompose the nitrate and should be sufficient to promote the crystallization of the oxide. At this temperature, however, the decomposition reaction described by equation (4) also becomes spontaneous (Fig.1).

Experimentally, the combustion reactions occur with uncontrolled explosion for the excess of urea used and the ignition become non-explosive. For this urea content, the theoretical flame temperature is $639^{\circ} \mathrm{C}$ for reaction equation (9) and the measured maximum temperature reached by the reaction was $569^{\circ} \mathrm{C}$. The excess amount of urea will affect significantly the combustion reaction and the ratio of fuel-to-nitrate can react completely with nitrate. In the case of glycine, carbohydrazide and citric acid used in the synthesis of the $\mathrm{ZnO}$ powders, based on the propellant chemistry [6], to calculate the total reducing valencies of the $\mathrm{C}_{2} \mathrm{H}_{5} \mathrm{NO}_{2}$ is $+9, \mathrm{CH}_{6} \mathrm{~N}_{4} \mathrm{O}$ is +8 and $\mathrm{C}_{6} \mathrm{H}_{8} \mathrm{O}_{7}$ is +18 . Thus, the stoichiometric composition of the redox mixture, in order to release the maximum energy for the reaction, demands that

$(-10)+\psi(+9)=0$ or $\psi=1.11$ mole of glycine used,

$(-10)+\psi(+8)=0$ or $\psi=1.25$ mole of carbohydrazide used and

$(-10)+\psi(+18)=0$ or $\psi=0.55$ mole of citric acid used.

Calculations of Stoichiometry of Fuel-oxidizer Mixture. Calculation of the stoichiometry of metal nitrate-fuels mixtures utilizes the principles of propellant chemistry [6] and employs the elemental stoichiometric coefficient $\left(\Phi_{\mathrm{e}}\right)$. This parameter uses the total oxidizing and reducing valencies of the components, which serve as numerical coefficients for the stoichiometric balance. When $\Phi_{\mathrm{e}}=1$ the mixture is stoichiometric and is known to release maximum energy in condensed fuel-oxidizer systems. The mixture is fuel-lean (deficient) when $\Phi_{\mathrm{e}}>1$ and rich when $\Phi_{\mathrm{e}}<1$. The oxidizer-to-fuel molar ratio required for a stoichiometric mixture is determined by summing the total oxidizing and reducing valencies in the oxidizer (zinc nitrate) and dividing by the sum of the total oxidizing and reducing valencies in the fuels such as urea, glycine, carbohydrazide and citric acid, as shown in equation (16) [17]. In these types of calculations, oxygen is considered to be the only oxidizing 
elements; carbon, hydrogen and metal cations are reducing elements; and nitrogen is neutral. Oxidizing elements have positive valencies and reducing elements have negative valencies. According to the concepts used in propellant criterion as described by Jain et al. [6]. The oxidizer/fuel molar ratio required for a stoichiometric mixture $\left(\Phi_{\mathrm{e}}=1\right)$ is determined by summing the total oxidizing and reducing valencies in the oxidizer compounds and dividing by the sum of the total oxidizing and reducing valencies in the fuel compounds. Considering the following elements are: $\mathrm{Zn}$ and $\mathrm{H}$ are considered as reducing elements with the valencies of +2 and +1 respectively. The element oxygen $(\mathrm{O})$ is considered as an oxidizing element with valency -2 . The valency of nitrogen is considered to be zero. For all the experiments, the metal nitrate materials such as zinc nitrate and different reducing agents like urea, glycine, carbohydrazide and citric acid are used.

Oxidizer/fuel ratio $=\frac{\Sigma \text { all oxidizing and reducing elements in oxidizer }}{(-1) \Sigma \text { oxidizing and reducing elements in fuel }}$

Based on these considerations, the fuel-to-oxidizer ratio calculated above. This ratio is required for the complete combustion of all materials.

Characterizations of As-synthesized Products. In combustion, the control of oxidant to fuel ratio should create a high heat induced from the reactions. Therefore, in order to use an exothermic reaction, the selection of a suitable ratio of oxidant to fuel is very important. A non-suitable ratio of nitrate to fuel makes some unwanted intermediate phases or unreacted raw materials. Generally, the fuel should be reacted slowly and act as a complex maker of cations. Complexes increase the metallic cation solubility and hence prohibit preferred crystallization during evaporation of the primary water. The fuel-stoichiometric composition indicates $\Phi_{\mathrm{e}}=1$, which fuel-lean (deficient) composition range shows $\Phi_{\mathrm{e}}>1$ and fuel-rich composition range means $\Phi_{\mathrm{e}}<1$, respectively. By definition fuel-lean mixtures have excess oxygen and it is observed that the molecular oxygen concentration decreases linearly with $\Phi$ untile $\Phi \sim 1$, where it is exhausted. Using the oxidizer relation of $\Phi_{\mathrm{e}}=1(\mathrm{O} / \mathrm{F})$, the energy released is at its maximum and an explosion reaction occurs, which is sustainable and self-propagating, transforming the initial mixture. 
Our first, experimental work is based on the mixture of reactants that oxidize easily (such as zinc nitrates) and suitable for organic fuels (such as urea) that acts as a reducing agent. In the second experimental work glycine $\left(\mathrm{C}_{2} \mathrm{H}_{5} \mathrm{NO}_{2}\right.$, MERCK pure chemicals) was used as a fuel, in order to synthesize $\mathrm{ZnO}$ powder. Third experimental work is based on zinc nitrite-carbohydrazide system to synthesize zinc oxide. In the case of using carbohydrazide as fuel, it reacted with the nitric acid group $\left(\mathrm{NO}_{\mathrm{x}=1,2,3}\right)$ and formed highly explosive $\mathrm{CO}\left(\mathrm{N}_{3}\right)_{2}$. In the fourth experimental work, Zinc nitrate and citric acid was used as fuel to synthesize $\mathrm{ZnO}$ powder. The weight fraction of urea and zinc nitrate was determined by balancing the oxidizing valences and reducing valences among the reactants. In a stoichiometric composition, oxidizing valence provided by the oxidizer and is equal to reducing valence from the fuel. The fuels was selected in seven different variation of the fuel/oxidant ratio such as fuel-deficient (below 1), equilibrium state (oxidant/fuel $=1.11$ ) and fuel rich (above 1.11). The fuel- deficient composition range have less fuel contents and fuel rich composition have more fuel contents of a stoichiometric composition, respectively.

The zinc nitrate and fuels were weighed, dissolved in required quantity of distilled water and homogenized on a magnetic stirrer. After mixing and homogenizing zinc nitrate with fuel is brought to silica crucible, the above-mentioned sample was placed into a household microwave (MW) oven (BPL India Limited, Bangalore, India, Model No. IFB, 17PG1S, microwave 700W, input range 210$230 \mathrm{~V}$-ac $50 \mathrm{~Hz}$, microwave frequency $2.45 \mathrm{GHz}$ ). The MW oven was always operated at its maximum power setting. The precursor mixture of water, metal nitrates and fuel decomposes, dehydrates and the sample was boils, froths, ignites and catches fire at a high temperature. The nitric acid group $\left(\mathrm{NO}_{3}{ }^{-}\right)$reacted with the fuel and intense heat was generated (the temperature rises to 1300-1500 $\left.{ }^{\circ} \mathrm{C}\right)$. At this temperature, the metal nitrates decompose to metal oxides and oxides of nitrogen and hence act as oxidizer for further combustion, which leads to a voluminous, foamy powder which occupies the entire volume of the reaction vessel is less than 3-4 minutes. The flame persisted for about 1 minute. The chemical energy released from the exothermic reaction between the metal nitrates and fuel can rapidly heat the system to high temperatures $\left(>1100{ }^{\circ} \mathrm{C}\right)$ without an 
external heat source. At the end of 5 min of MW heating within a well ventilated fume hood, the sample silica was taken out and their contents were let to cool down to room temperature (RT) in ambient atmosphere and the next few minutes it is ready for the $\mathrm{ZnO}$ nanomaterial. The foam was then lightly ground in an agate-mortor to obtain fine particles. Glycine and carbohydrazide fuel used $\mathrm{ZnO}$, the measured temperature rose to $1200-1300{ }^{\circ} \mathrm{C}$ instantaneously flame and combustion. They are synthesized into four batches in three different fuel ratio of $\mathrm{ZnO}$ powders with the variation of the fuel/oxidant ratio. The various ratio between the adding of fuel in fuel- deficient $\left(\Phi_{\mathrm{e}}>1\right)$, equilibrium state $\left(\Phi_{\mathrm{e}}=1\right)$ and fuel-rich $\left(\Phi_{\mathrm{e}}<1\right)$ state. In the fuel- deficient state is considering to the presence of $\mathrm{Zn}$ or $\mathrm{ZnO}$. The auto ignition exists for a limited range of fuel-to-oxidant ratio, above and below the ratio calculated by the concept of propellant chemistry, depending on the nature of fuels.

Fig. 10 shows the XRD results of as-synthesized $\mathrm{ZnO}$ powder obtained from the three different amount of urea as a fuel was selected for this work. It denotes, the case when the $\Psi$ is 1 (fueldeficient), $\Psi=1.667$ (fuel-stoichiometric)) and $\Psi=3$ (fuel-rich)) of the stoichiometric composition ratio, respectively. The XRD pattern shows that the synthesized fuel-deficient composition powder was not a single-phase and some additional peaks are obtained due to incomplete combustion reaction. When the fuel is stoichiometric mixtures ( $\Psi=1.667$ i.e., the oxygen content of zinc nitrate is exactly sufficient to consume/oxidize the fuel), single-phase $\mathrm{ZnO}$ powder was obtained. 


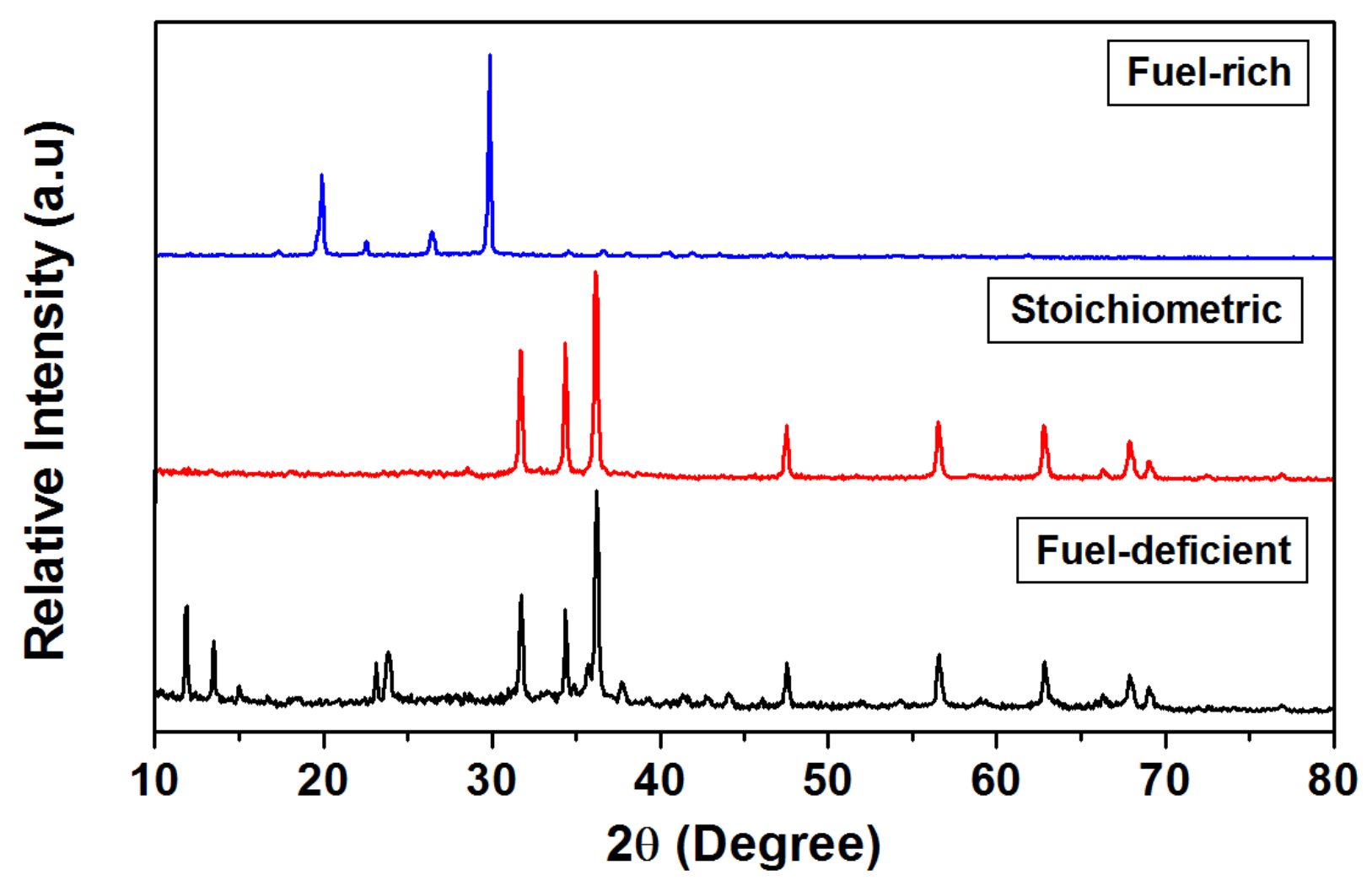

Fig. 10. XRD patterns of the as-prepared $\mathrm{ZnO}$ powders with different molar ratio of urea-to-zinc nitrate. (a) $\Psi=1$ (fuel-deficient), (b) $\Psi=1.667$ (stoichiometric) and (c) $\Psi=3$ (fuel-rich).

On the other hand, when the precursor mixtures contain excess fuel (fuel-rich composition), the reaction is not complet due to the excess of oxygen in the combustion process. This experimental result (Fig.11) shows the XRD patterns of the as-synthesized $\mathrm{ZnO}$ powders synthesized using glycine-nitrate process. Generally, in these cases, oxide powders were synthesized by adding the fuel in stoichiometric equilibrium state (oxidant/fuel), a lean fuel or fuel-rich state considering on the degree of explosion about self-combustion, based on the thermochemical calculation of a fueloxidant mixtures. 


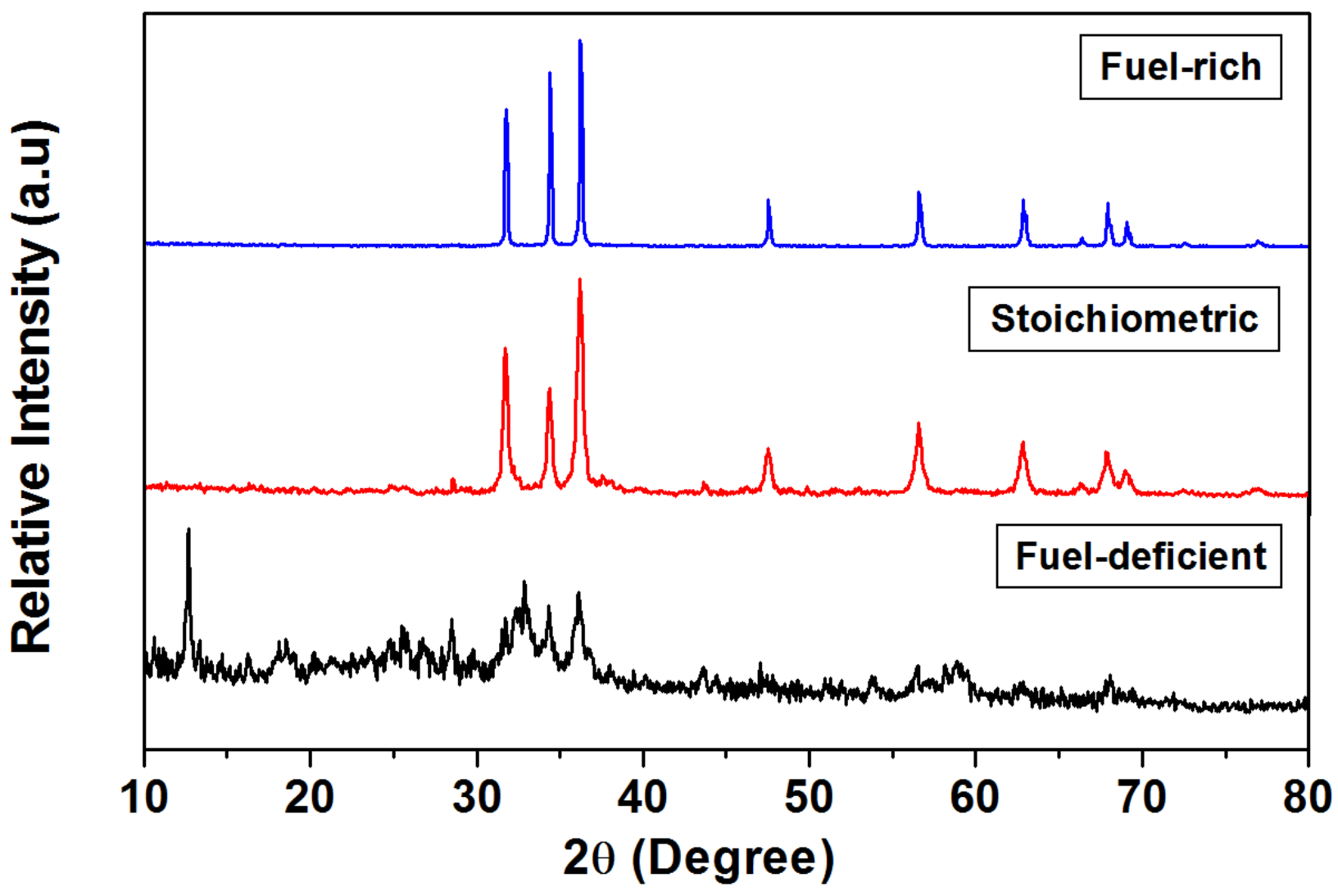

Fig.11. XRD patterns of the as-prepared $\mathrm{ZnO}$ powders with different molar ratio of glycine-to-zinc nitrate. (a) $\Phi=0.8$ (fuel-deficient), (b) $\Phi=1.11$ (stoichiometric) and (c) $\Phi=1.6$ (fuel-rich).

Three different $\mathrm{ZnO}$ powders were synthesized with the variation of the fuel/oxidant ratio $(\Psi=$ 0.7, 1.11 and 2). As can be seen, the relatively low signal/noise ratio and some unknown diffraction peaks indicate that the as-synthesized powder prepared using $\psi=0.7$ (fuel-deficient) consisted with insufficiently developed crystalline $\mathrm{ZnO}$ and impurities because the fuel content is inadequate. So it could not react completely and relatively slow with the zinc nitrate to release enough heat (essentially flameless reaction) to form the well-developed phase of $\mathrm{ZnO}$. However, the impurities probably came from amine and nitric acid groups, which were not completely combusted or adsorbed on the $\mathrm{ZnO}$ powder surfaces. The amine group came from the glycine during the selfcombustion of the solution. The nitric acid group was the impurity remaining without contributing to 
combustion. It is easy to obtain single-phase $\mathrm{ZnO}$ powders regardless of the variation of the fuel/oxidant ratio.

Especially the $\mathrm{ZnO}$ powder with fuel/oxidant ratio of 1.11 showed highest XRD peaks that indicates best crystalline quality. When $\psi=1.11$ (equilibrium state-stoichiometric) and $\psi=1.6$ (fuelrich), the reaction is a fast one. Since the fuel-to-oxidant ratio is equivalant or more, the oxygen content in the precursor is the main source of oxygen required for combustion reaction. Once the oxygen comes from $\mathrm{NO}_{3}{ }^{-}$it immediately reacts with glycine and oxidizes of the fuel and the results of the product contain single-phased $\mathrm{ZnO}$ because only the characteristic peaks of $\mathrm{ZnO}$ were observed. In the case of using carbohydrazide as fuel, it reacted with nitric acid group $\left(\mathrm{NO}_{\mathrm{x}=1,2,3)}\right.$ and formed highly explosive $\mathrm{CO}\left(\mathrm{N}_{3}\right)_{2}$. At this point, the temperature rose to $1300-1500^{\circ} \mathrm{C}$ instantaneously with fire and combustion. The $\mathrm{ZnO}$ powder was synthesized using this heat. The crystalline phases of the synthesized powders were confirmed by XRD patterns of Fig. 12. When the ratio of fuel $(\Psi)$ was $0.6,1.25$ and 2 , the XRD patterns showed that the fuel-deficient condition, carbohydrazide was completely consumed but the nitric acid group partially remained. 


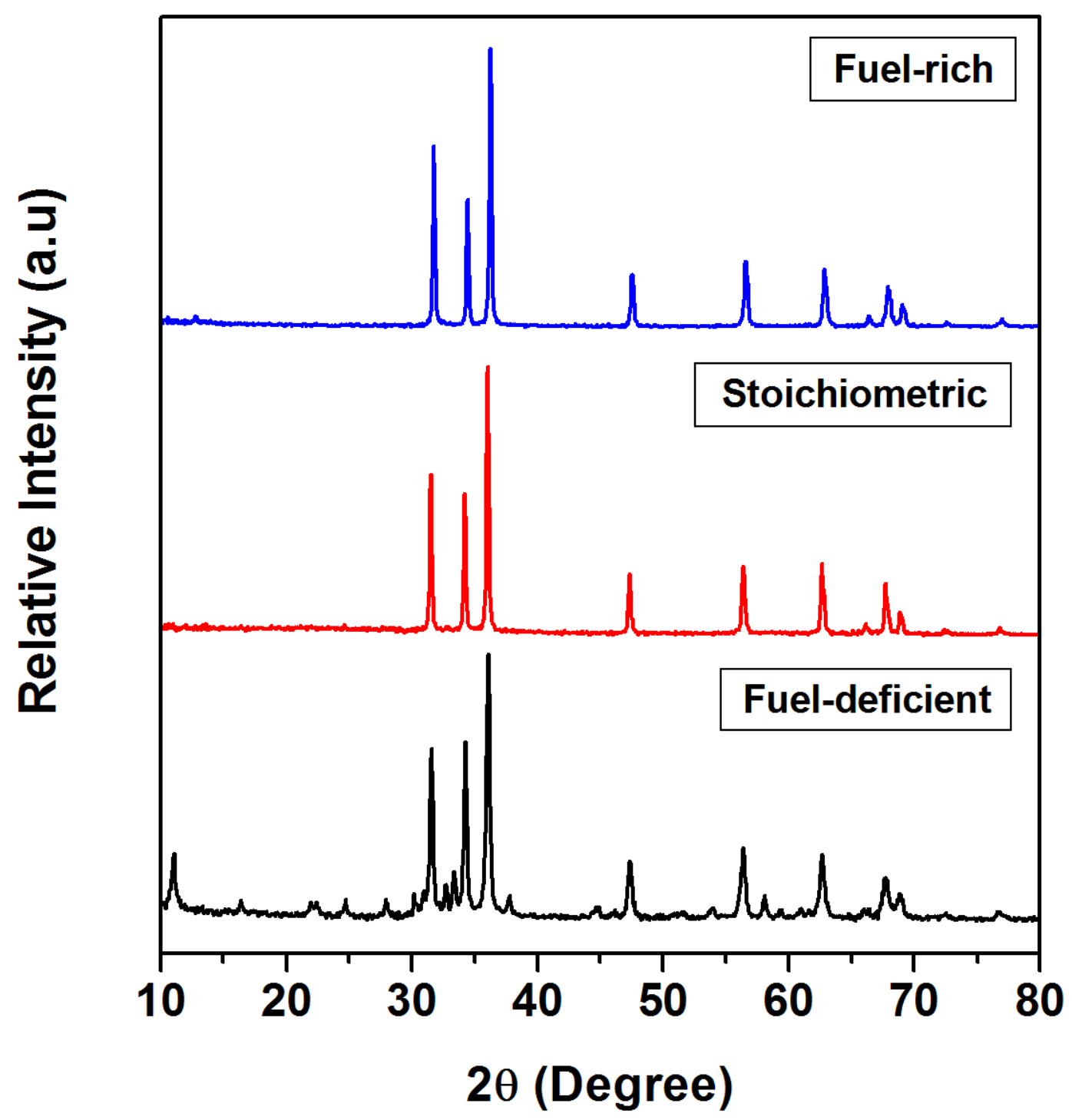

Fig.12. XRD patterns for as-prepared $\mathrm{ZnO}$ powders prepared with carbohydrazide by microwaveassisted combustion process. (a) $\Psi=0.6$ (fuel-deficient), (b) $\Psi=1.25$ (stoichiometric) and (c) $\Psi=2$ (fuel-rich).

The XRD patterns shows that the fuel deficient condition, a small residuals peak due to the incomplete combustion reaction. But the peaks of single-phase $\mathrm{ZnO}$ started to form only when the fuel-to-oxidant ratio was equal or higher than 1.25 (stoichiometric). At the ratio of 1.25 , the intensity of the peaks is very weak, even though the peak of pure single-phase $\mathrm{ZnO}$ was completely formed without any impurities. The carbohydrazide ratio of 1.25 is corresponding to the reaction formula to form complete $\mathrm{CO}\left(\mathrm{N}_{3}\right)_{2}$ from the reaction between nitric acid group and carbohydrazide. When the 
combustion reaction is occurred, the degree of explosion looks like similar although the ratio was increased. However, it showed a little bit higher degree of explosion when the ratio exceeded 1.25. At the ratio of 1.25 , the fuel (carbohydrazide) and oxidant (zinc nitric) were completely consumed to form highly explosive $\mathrm{CO}\left(\mathrm{N}_{3}\right)_{2}$. In the case of excess fuel (ratio higher than 1.25), the remaining fuel was anticipated to decompose and evaporate in air atmosphere. Fig. 13 shows the XRD patterns of as-prepared $\mathrm{ZnO}$ powders at three types of citric acid fuel to raw material ratios $(\Psi)$ of $0.1,0.55$ and 1.0 by the combustion process. The stoichiometric and fuel-rich condition gave better results. Therefore, it is possible to suggest that the citric acid can bring down the formation temperature of the product due to the easier complex formation and homogeneous. All the XRD patterns and searchmatch database analysis confirmed that the as-synthesized powders have the phase composition of wurtzite $\mathrm{ZnO}$ with P63mc structure [16].

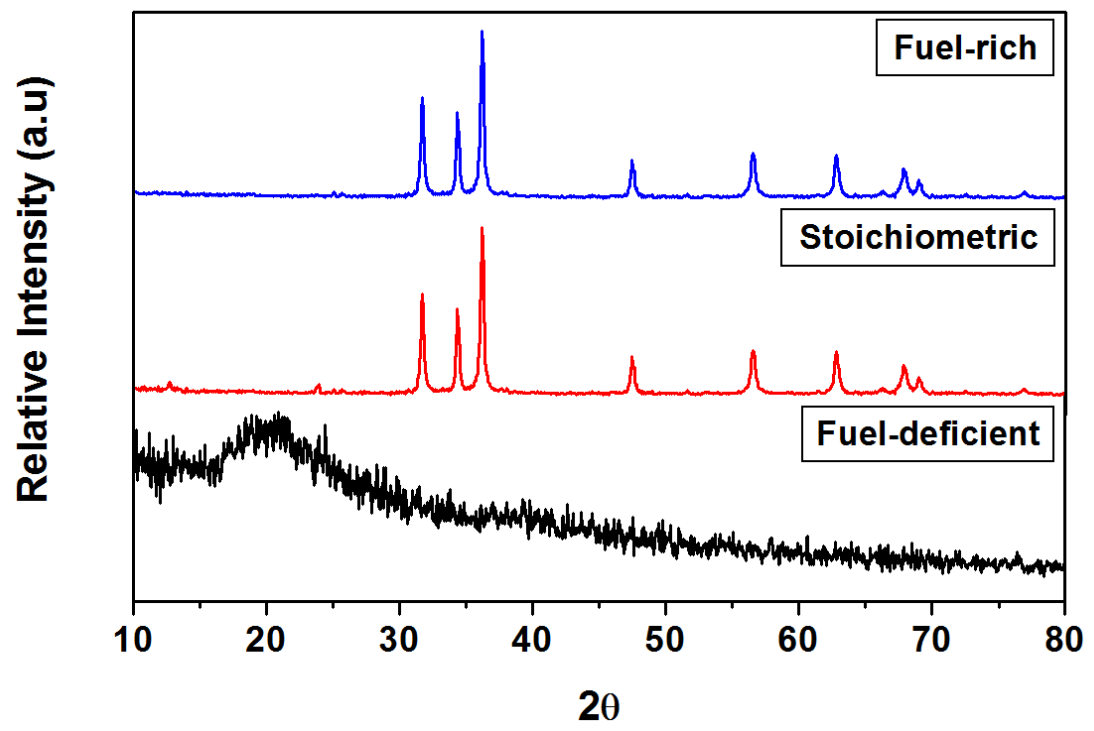

Fig.13. XRD patterns of the as-prepared $\mathrm{ZnO}$ powders with different molar ratio of citric acid-tozinc nitrate. (a) $\Psi=0.1$ (fuel-deficient), (b) $\Psi=0.55$ (stoichiometric) and (c) $\Phi_{\mathrm{e}}=1$ (fuel-rich).

The stoichiometric condition of the as-prepared $\mathrm{ZnO}$ powders morphology can be observed in the SEM photomicrographs shown in Fig. 14. The particle size was greatly dependent on the type of fuels showing significantly different morphologies. The aggregates observed are mainly constituted 
by clusters of several tiny spheres weakly agglomerated. Finest particles were obtained when citric acid were used. Because the formation temperature of the product due to the easier complex formation and homogeneous gel, thus the crystallite sizes are smaller in comparison to other fuels.
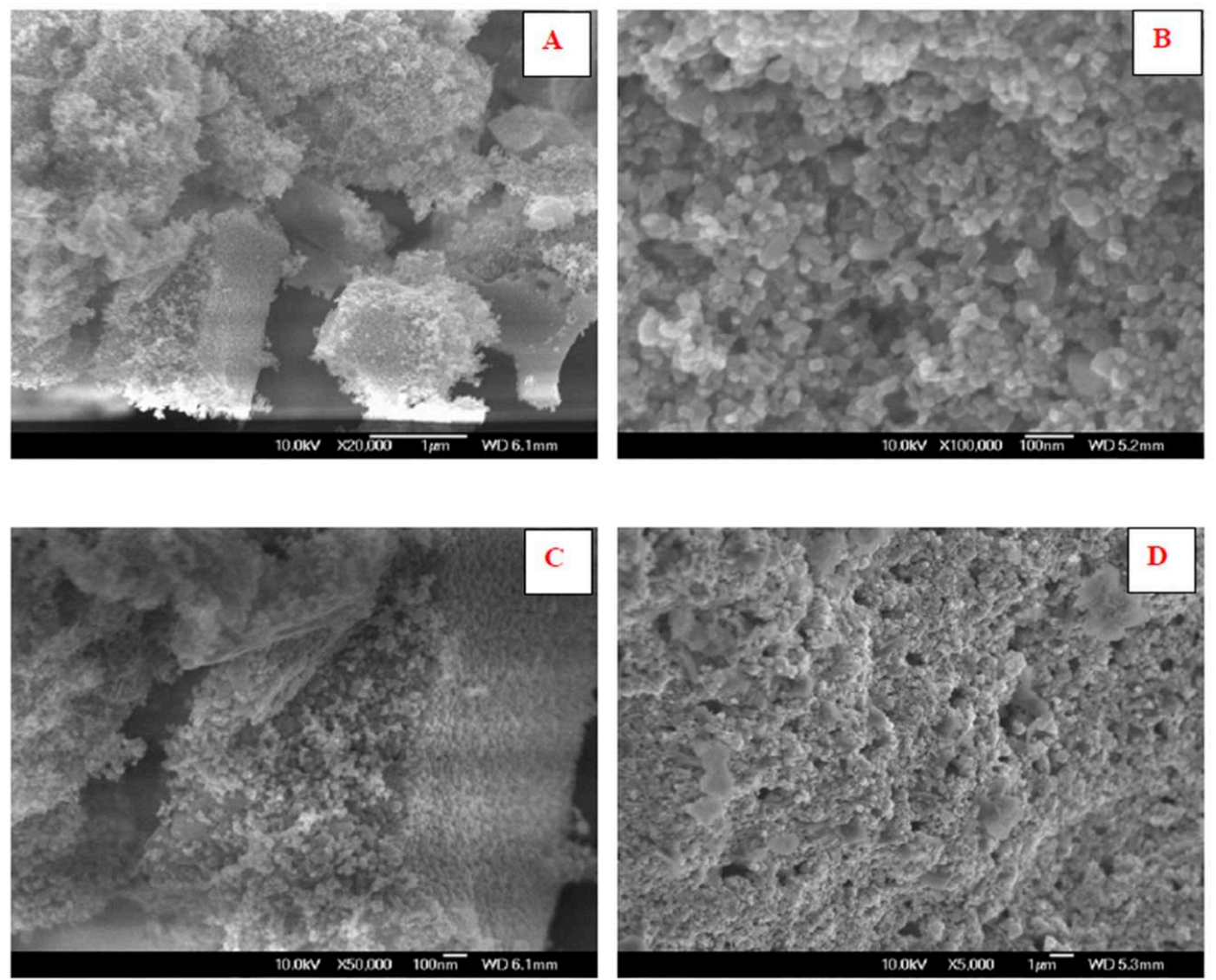

Fig. 14. SEM micrographs of the stoichiometric condition of the as-prepared $\mathrm{ZnO}$ powder using (a) Urea, (b) Glycine, (c) carbohydrazide and (d) citric acid.

\section{Conclusion}

In this study, we have presented the microwave-assisted combustion process to produce $\mathrm{ZnO}$ powders in air atmosphere. Microwave processing of heating materials is fundamentally different from conventional ones, where the volumetric heating caused multiple ignition points throughout the solution and resulted in a uniform product. Utilization of organic compounds, acting as fuels and zinc nitrate acting as the duel roles of zinc source and oxidant, in conjunction with mixing the reactants directly without adding other solutions (like $\mathrm{NH}_{4} \mathrm{OH}$, etc.,) are the key advantages of this 
method. When compared with other methods, it is a simple, quick and inexpensive single-step reaction. The amount of the fuel or complexing agent has been fixed according to the concept of propellant chemistry. From the XRD patterns of as-synthesized $\mathrm{ZnO}$ powders, it is possible to find out the best molar ratio of fuel-to-zinc nitrate is important in obtaining pure single-phase crystalline $\mathrm{ZnO}$ powder by combustion $\psi$ value of 1.667 (urea), 1.11 (glycine), 1.25 (carbohydrazide) and 0.55 (citric acid) was selected for getting better results as a representative stoichiometric conditions. So the stoichiometric condition ratio was found to produce favorable powder characteristics. When glycine and carbohydrazide was used, the heat released during the combustion was more and as a result the combustion reaction enthalpy was more which gives a complete combustion and small crystallite $\mathrm{ZnO}$ powder. But $\mathrm{ZnO}$ prepared with carbohydrazide fueled had bigger crystallite size compare to other fuels (urea and citric acid). The combustion reaction of citric acid fuel used $\mathrm{ZnO}$ powder produces lower flame temperature but the crystallite size of the powder was smaller compared to urea and carbohydrazide. An interpretation based on the measurement of temperature ( $\left.\mathrm{T}_{\text {measured }}\right)$ and the estimation of amount of gases produced during the combustion reaction, the effect of fuel-to-oxidant molar ratio on the powder characteristics have been explained. It is found that the $\mathrm{T}_{\text {measured }}$ increases with increasing the value of $\psi$ and then decreases with further increase in the molar ratio. Furthermore, the adiabatic flame temperature $\left(\mathrm{T}_{\mathrm{ad}}\right)$ can be calculated theoretically according to the thermodynamic concept. However, as expected, both the amount of produced gases and the $\mathrm{T}_{\mathrm{ad}}$ increase substantially with the amount of the fuel used during the combustion reaction. The combustion reaction using stoichiometric amount of urea produces lower flame temperature and higher number of gas molecules than those of stoichiometric amount of glycine, carbohydrazide and citric acid. A higher flame temperature $\left(\mathrm{T}_{\mathrm{ad}}\right)$ of the powders was obtained from carbohydrazide and glycine. The probable reasons of lower flame temperature in higher urea containing batches are due to the lower enthalpy of urea along with higher gaseous volume released from the reaction. 


\section{References}

[1] K.C. Patil, S.T. Aruna, T. Mimani, Combustion synthesis: an update, Curr. Opinion. Solid State Mater. Sci. 6 (2002) 507-512.

[2] A. Varma, A.S. Mukasyan, K.T. Deshpande, P. Pranda, P.R. Erri, Mater. Res. Soc. Symp. Proc. 800 (2004) AA41. (http://journals.cambridge.org/abstract_S1946427400095269)

[3] A.S Mukasyan, P. Epstein, P. Dinka, Solution combustion synthesis of nanomaterials, Proc. Combustion Institute 31(2) (2007) 1789-1795.

[4] Poonam Sharma, Gurmeet Singh Lotey, Sukhpreet Singh, N. K. Verma, Solutioncombustion: The versatile route to synthesize silver nanoparticles, J. Nanopart. Res. 13 (2011) 2553-2561

[5] Y. Li, J. Zhao, L. Qiang, J. Jiang, Combustion synthesis of zinc ferrite powders in oxygen, J. Alloys Compd. 373 (2004) 298-303.

[6] S.R. Jain, K.C. Adiga, V.R.P. Verneker, A new approach to thermochemical calculations of condensed fuel-oxidizer mixtures, Combustion Flame 40 (1981) 71-79.

[7] S.T. Aruna, A.S. Mukasyan, Combustion synthesis and nanomaterials, Curr. Opin. Solid. State. Mater. Sci. 12 (2008) 44-50.

[8] L. A. Chick, L.R. Pederson, G.D. Maupin, J. L. Bates, L. E. Thomas, G.J. Exarhos, Glycinenitrate combustion synthesis of oxide ceramic powders, Mater. Lett. 10 (1990) 6-12.

[9] L.C. Nehru, V. Swaminathan, C. Sanjeeviraja, Rapid synthesis of nanocrystalline ZnO by a microwave-assisted combustion method, Powder Technol. 226 (2012) 29-33.

[10] R.D. Purohit, S. Saha, A.K. Tyagi, Nanocrystalline ceria powders through citrate-nitrate combustion, J. Nanosci. Nanotechnol. 6 (2006) 209-214. 
[11] C.-C. Hwang, T.-Y. Wu, Synthesis and characterization of nanocrystalline ZnO powders by a novel combustion synthesis method, Mater. Sci. Eng. B 111 (2004) 197-206.

[12] V.C. Sousa, A.M. Segadães, M.R. Morelli, R.H.G.A. Kiminami, Combustion synthesized ZnO powders for varistor ceramics, Int. J. Inorg. Mater. 1 (1999) 235-241.

[13] R.J. Sibey, R.A. Alberty, Physical Chemistry, third ed., Wiley, New York, NY, 2000.

[14] R.K. Selvan, C.O. Augustin, L. John Berchmans, R. Saraswathi, Combustion synthesis of CuFe2O4, Mater. Res. Bull. 38 (2003) 41-54.

[15] C.C. Hwang, C.-Y. Wu, J. Wan, J.-S. Tsai, Development of a novel combustion synthesis method for synthesizing of ceramic oxide powders, Mater. Sci. Eng. B 111 (2004) 49-56.

[16] Joint Committee on Powder Diffraction Standards (JCPDS) (JCPDS-ICDD), file number No.: 36-1451.

[17] A. Jegatha Christy, L.C. Nehru, M. Umadevi, A novel combustion method to prepare $\mathrm{CuO}$ nanorods and its antimicrobial and photocatalytic activities, Powder Technol. 235 (2013) 783-786. 